\title{
Ordenación de usos agrarios en áreas protegidas de media montaña mediterránea. Estudio de la Sierra Morena andaluza
}

\author{
Agricultural uses management in middle Mediterranean protected \\ mountainous areas. Study in the Andalusian Sierra Morena
}

\author{
Rafael Garzón-García ${ }^{1^{*}}$ (iD) \\ Rafael Vega-Pozuelo² (iD
}

\section{Resumen}

Se analiza la vinculación entre áreas protegidas y actividades de base agraria, en particular en entornos de media montaña mediterránea. En ellos dicha vinculación goza de una especial relevancia a tenor de factores como la variedad y riqueza de las formas de aprovechamiento agrario y su compatibilidad —en frágil equilibrio - con la conservación de elevadas cotas de cualificación ambiental y paisajística. El importante incremento durante las últimas décadas de las áreas protegidas de gran extensión y visión multifuncional - particularmente bajo la categoría de Parque- en tales entornos así lo muestra. Se estudia, con el apoyo de fuentes cartográficas, estadísticas y del trabajo de campo, la situación general registrada en los parques naturales de la Sierra Morena andaluza. Se constatará la dispar consideración de los agrosistemas entre parques, así como los logros y carencias en la ordenación y gestión de los principales usos agrarios y la incidencia en su evolución.

Palabras clave: actividad agraria; áreas protegidas; media montaña mediterránea; Parque Natural; multifuncionalidad; Sierra Morena andaluza.

\footnotetext{
Abstract

The connection between protected areas and agrarian-based activities - particularly in Mediterranean mountainous environments - is analysed. This connection has a special relevance according to factors such as the variety and richness of the forms of agricultural use and their compatibility - in a fragile balance - with the conservation of environments and landscapes. Evidence is the significant increase in recent decades of large and multifunctional protected areas - particularly under the category of Park. With the support of cartographic sources, statistics, and fieldwork, the general situation in the natural parks of the Andalusian Sierra Morena is studied. The various agrosystems in different parks are verified, as well as the achievements and shortcomings in the organisation and management of the main agricultural uses and the impact on their development.

Keywords: agricultural activity; protected areas; Mediterranean mid-mountain; Natural Park; multifunctionality; Andalusian Sierra Morena.

1 Departamento de Ciencias Sociales, Filosofía, Geografía y Traducción e Interpretación; Grupo de Investigación Estudios de Geografía; Universidad de Córdoba, España. rafael.garzon@uco.es. * Autor para correspondencia

2 Departamento de Ciencias Sociales, Filosofía, Geografía y Traducción e Interpretación; Grupo de Investigación Estudios de Geografía; Universidad de Córdoba, España. rvega@uco.es 


\section{Introducción}

Según la definición más aceptada, la aportada por la Unión Internacional para la Conservación de la Naturaleza (UICN, en inglés IUCN), un espacio natural protegido o área protegida corresponde a "una superficie de tierra y/o mar especialmente dedicada a la protección y mantenimiento de la diversidad biológica y de los recursos naturales y culturales asociados, y gestionada a través de eficaces instrumentos legales o de otro tipo" (Corraliza, Valero y García, 2002, p. 62). De dicha definición se infiere que se trata de espacios geográficamente delimitados, que cuentan con un especial valor natural y, en no pocos casos, cultural, a los que se dota de un régimen de protección legal, lo que se acompaña de un manejo o gestión orientada a alcanzar los objetivos planteados.

Como se infiere de dicha definición, los espacios naturales, entendidos como aquellos donde los procesos y dinámicas naturales se hacen aún patentes con nitidez, tan solo en pocos casos resultan completamente ajenos a la intervención más o menos directa del hombre, que busca principalmente en tales espacios la obtención de recursos vivos de diversa índole, bajo la forma de variadas actividades agrarias; podría hablarse pues, con la sola excepción de aquellas áreas protegidas radicadas en entornos especialmente hostiles para la presencia humana por sus condiciones climáticas y de relieve, de una evidente correspondencia territorial entre áreas protegidas y espacios agrarios (de carácter tradicional y respetuosos —en un grado notable - de la base biofísica sustentadora).

En relación con ello, cabe remarcar el cambio conceptual operado en la visión de las áreas protegidas: desde una visión inicialmente aislacionista y restrictiva — centrada en el objetivo primordial de la conservación de espacios naturales muy valiosos o excepcionales - a una más reciente - un nuevo paradigma, en palabras de Phillips (2003) — de carácter más abierto e integrador, fundamentada en el entendimiento de tales áreas en tanto que piezas clave y de especial valor en el contexto de la matriz territorial y ecológica en que se enmarcan y con la que interactúan (Spellerberg, 1994; Naughton-Treves, Holland y Brandon, 2005; Chape, Spalding y Jenkins, 2008). Se ha apuntado que lo característico de las políticas más avanzadas de protección de espacios han sido los planteamientos multifuncionales e integrados (Naughton-Treves et al., 2005; Chape et al., 2008; Dudley, 2008; McDonald y Boucher, 2011). De este modo, las políticas de áreas protegidas, sin renunciar al tradicional objetivo conservacionista (aún predominante, o incluso exclusivo, en ciertos espacios de muy bajo grado de humanización), han incorporado o reforzado una diversidad de funciones con trasfondo social, tales como la educación ambiental, la investigación científica, el uso turístico-recreativo, además de los usos tradicionales de base agraria.

En todo caso, la disparidad territorial de los espacios dotados de relevantes valores naturales justifica la heterogeneidad en el diseño geográfico y formas de gestión de las áreas protegidas, en un contexto de proliferación de las mismas a escala global. Prueba de ello son las categorías de protección reconocidas por la UICN, referente básico para la definición de figuras protectoras en los diversos contextos nacionales (Tabla 1).

Tabla 1. Síntesis de los caracteres básicos de las categorías protectoras establecidas por la clasificación de la UICN (1994)

\begin{tabular}{|c|l|}
\hline Categoría & \multicolumn{1}{c|}{ Definición } \\
\hline I- Reserva Natural Estricta & Área protegida manejada principalmente con fines científicos o fines de protección de la naturaleza. \\
\hline II- Parque Nacional & $\begin{array}{l}\text { Área protegida manejada principalmente para la conservación de ecosistemas y con fines de } \\
\text { recreación }\end{array}$ \\
\hline III- Monumento Natural & $\begin{array}{l}\text { Área protegida manejada principalmente para la conservación de sus características naturales } \\
\text { específicas }\end{array}$ \\
\hline $\begin{array}{c}\text { IV- Área de Manejo de } \\
\text { Hábitats/Especies }\end{array}$ & $\begin{array}{l}\text { Espacio protegido cuyo manejo deberá dedicarse principalmente hacia la conservación, con } \\
\text { intervención activa en el ámbito de la gestión. }\end{array}$ \\
\hline $\begin{array}{c}\text { V- Paisaje Terrestre y } \\
\text { Marino Protegido }\end{array}$ & $\begin{array}{l}\text { Área protegida manejada principalmente para la conservación de paisajes terrestres y marinos, y } \\
\text { con fines recreativos. } \\
\text { producido una zona de carácter definido con importantes valores estéticos, ecológicos y/o } \\
\text { culturales, y que a menudo albergan una rica diversidad biológica. }\end{array}$ \\
\hline $\begin{array}{c}\text { VI- Área Protegida con } \\
\text { Recursos Manejados }\end{array}$ & $\begin{array}{l}\text { Áreas protegidas y manejadas principalmente para la utilización sostenible de los ecosistemas } \\
\text { naturales. }\end{array}$ \\
\hline
\end{tabular}

Fuente: Corraliza et al. (2002) 
Como puede advertirse, las categorías UICN aglutinan la totalidad de casuísticas posibles de protección de áreas naturales relevantes. Cabe destacar, a los efectos de este trabajo, aquellas categorías — como las V y VI- cuya conceptuación manifiesta con nitidez la flexibilidad y dimensión multifuncional en la gestión antes apuntadas.

Tales categorías resultan de especial aplicabilidad en aquellos contextos geográficos donde la presencia humana ha resultado históricamente más evidente en sus espacios naturales de mayor cualificación, es decir, donde la identificación territorial espacio natural-espacio agrario se ha tornado más clara. El espacio geográfico mediterráneo responde muy fielmente a tales caracteres, aún más en particular en sus numerosas montañas (Mazurek y Blanchemanche, 1992; Mata, 2012). Estas resultan espacios profundamente trabajados y modelados por la mano el hombre, gozando en numerosos sectores de un elevado valor ambiental y paisajístico — pudiendo hablar de agrosistemas o, incluso, agroecosistemas (Gómez, 2007) - , lo que explica su recurrente conservación, bajo distintas figuras de protección (concreción de las categorías IUCN), entre las que ha resultado predominante, al menos en el contexto normativo español, la de Parque ${ }^{3}$.

Sobre esta base, en las páginas que siguen se plantea un análisis específico respecto de la realidad usos agrarios-áreas protegidas, aplicado al caso de la media montaña mediterránea y concretado geográficamente en la Sierra Morena andaluza, uno de sus ámbitos paradigmáticos y privilegiados a escala española. El análisis propuesto se centra en la evolución de los usos agrarios y de los agrosistemas que los sustentan, tratando de reconocer la incidencia específica —en forma de logros, posibles carencias, conflictos y posibilidades— de la protección legal en ello.

\section{Metodología}

La definición y articulación de los fundamentos epistemológicos del trabajo se ha sustentado en el manejo de fuentes bibliográficas especializadas, relativas a tres aspectos clave: la conceptualización de las áreas protegidas, la caracterización de la agrarización mediterránea, y la consideración de aquellas aportaciones centradas en el análisis de la relación usos agrarios-espacios protegidos.

Por su parte, para el estudio específico de la unidad territorial de referencia — la Sierra Morena andaluza - se ha adoptado un enfoque metodológico dual, que permite estructurar el análisis en un plano funcional (relativo a los procesos o dinámicas) y otro físico (relativo a la plasmación sobre el terreno de tales procesos). Dicho enfoque posibilita un acercamiento sistemático y riguroso al objeto de estudio, ya que ambos planos, en estrecha interrelación, constituyen las dos caras de cualquier realidad territorial. En este trabajo, el plano funcional remite a los usos o actividades agrarias, mientras que el plano físico lo hace a la concreción de las actividades agrarias en sectores territoriales bien reconocibles, los agrosistemas. A partir de este planteamiento metodológico, se ha hecho uso de varios tipos de fuentes: bibliográficas, cartográficas, planificación ambiental, fuentes documentales y estadísticas, y trabajo de campo.

En este sentido, las fuentes bibliográficas han permitido la caracterización básica de Sierra Morena como espacio de antigua humanización y agrarización, caracterizado por las diferentes rupturas de su equilibrio agroecológico, con especial intensidad desde el siglo XIX y hasta la actualidad. El análisis de la configuración actual de los espacios y paisajes agrarios mariánicos, en particular aquellos localizados en el interior de sus parques naturales, se ha sustentado tanto en el propio manejo bibliográfico, en el empleo de cartografía digital oficial (Datos Espaciales de Referencia de Andalucía [DERA], Sistema de Información sobre Ocupación del Suelo en España [SIOSE] y CORINE Land Cover) y en el exhaustivo trabajo de campo desarrollado sobre el terreno. Tales fuentes han permitido la contrastación de la realidad agroecológica de la Sierra Morena andaluza con su protección legal. De especial interés resulta el empleo de la cartografía digital ambiental (SIOSE y CORINE Land Cover), ya que ha permitido, a partir del tratamiento mediante SIG, la obtención de las superficies exactas de los agrosistemas para varios años de referencia (aquellos para los que se han elaborado dichas fuentes cartográficas), pudiendo establecer una secuencia evolutiva, lo que constituye una de las principales aportaciones del trabajo (Anexos 1 y 2).

\footnotetext{
3 Categoría reconocida como tal en la legislación española de áreas protegidas: inicialmente en la derogada Ley 4/1989, de 27 de marzo, de Conservación de los Espacios Naturales y la Flora y Fauna Silvestres, y actualmente en la Ley 42/2007, de 13 de diciembre del Patrimonio Natural y la Biodiversidad (art. 30).
} 
Finalmente, el análisis se culmina con la consideración específica de la ordenación y evolución de los usos agrarios que sustentan los principales agrosistemas en los parques naturales de Sierra Morena. Para ello se ha recurrido al manejo de sus instrumentos de planificación ambiental (Plan de Ordenación de los Recursos Naturales [PORN] y Plan Rector de Uso y Gestión [PRUG]), así como a fuentes estadísticas y documentales (destacando las Memorias de Actividades de los parques) y al trabajo de campo, para la observación de la dinámica agraria y su incidencia sobre los territorios protegidos.

\section{Resultados}

El presente apartado se estructura en cuatro epígrafes que se ordenan según una secuencia lógica llevada a cabo en la investigación.

\subsection{Caracterización general de la agrarización en la montaña mediterránea}

La cuenca mediterránea, región natural reconocible por sus caracteres físicos bien definidos, sobre todo de carácter climático (Gómez, 2007), se ha conformado ya desde el Mesolítico como un espacio antropizado, concretado en lo esencial en un proceso de agrarización expandido por la práctica totalidad de la cuenca y singularizado por su dinamismo y pluralidad de manifestaciones funcionales y paisajísticas (Zoido, 2007).

Cabe hablar, pues, de un paisaje rural mediterráneo o, más bien, de múltiples paisajes rurales mediterráneos, resultado de un histórico proceso de acondicionamiento de un sustrato físico-natural de condiciones frecuentemente hostiles (González, 1992; Gómez, 2007). Dicha antropización se ha hallado y aún hoy se halla en constante mutación, al generarse a partir de una sucesión de equilibrios hombre-medio natural muy diversificados (Mazurek y Blanchemanche, 1992). Y es en la media y baja montaña (excluidos los sectores de altas cumbres, de muy escasa o nula humanización) donde el equilibrio u orden territorial mediterráneo ha resultado más imprescindible y al mismo tiempo complejo, a tenor de las mayores limitaciones y fragilidad del medio (Ojeda, 2006; Mata, 2012).

Prueba de ello han sido las recurrentes rupturas de dicho orden, en forma de cambios de los equilibrios agroecológicos, lo que ha conllevado diversos procesos de readaptación o recuperación del equilibrio (Zoido, 2007). La conjunción de todos los factores referidos explica la complejidad, diversidad y dinamismo en el plano territorial y paisajístico de las montañas mediterráneas, en tanto que expresión de "unas complejas culturas en las que dominan lo diverso, lo pequeño, lo relacional, lo dinámico, lo domesticado y lo simbólico" (Ojeda, 2006, p. 181). Se plantea así el gran reto de fondo de la integración entre las viejas y nuevas formas de aprovechamiento - esencialmente agrarias-y la conservación y mejora de los valores naturales y paisajísticos.

\subsection{Evolución y caracterización actual de los agrosistemas de Sierra Morena}

El macizo de Sierra Morena, en su sector andaluz, responde en lo esencial al patrón dibujado de montaña media mediterránea, si bien desde una innegable especificidad. Se singulariza por su notable complejidad orográfica y el predominio de suelos pobres sobre un sustrato principalmente silíceo. Pese a su escasa población - en contraste, sobre todo, con la gran depresión bética que lo delimita por el sur - se halla humanizado desde antiguo, en virtud de la generalización de unos usos agrarios de carácter esencialmente extensivo —forestales, ganaderos y cinegéticos (Rivera, 1992; Valle, 2001)—, lo que determina su elevado grado de conservación general, incluso con determinados sectores de excepcional valor ecológico (Ojeda y Silva, 2002; Mulero y Silva, 2013).

La Sierra Morena andaluza se define por su acusada diversidad, riqueza y dinamismo territorial y paisajístico, lo que se explica, además de por los condicionantes físico-naturales, por la variedad histórica de formas de aprovechamiento agrario y de su concreción en agrosistemas o agroecosistemas (Valle, 1981; Zoido, 2012). En dicho proceso cabe destacar sobremanera la doble ruptura —o quiebra- de los equilibrios agroecológicos registrada durante los dos últimos siglos (Roux, 1975; Valle, 2001), lo que ha conducido a la situación actual.

Ésta incluye la preservación de ciertos agrosistemas precedentes, la reestructuración de otros, e incluso casuísticas de abandono o regresión agraria y consiguiente artificialización. Se ofrece acto seguido un recorrido por los principales sistemas y paisajes agrarios de la Sierra Morena andaluza, que muestran 
una plasmación territorial claramente dispar, destacando sobremanera el contraste entre la continuidad superficial de ciertos agrosistemas y el mosaicismo vegetal y paisajístico patente en otros ámbitos del macizo, principalmente en su mitad occidental (Figura 2).

Quizá el agroecosistema más emblemático de Sierra Morena —y de gran parte de las sierras y altiplanicies del centro-oeste de la Península Ibérica- son las dehesas ganaderas. Estas alcanzan una muy notoria representación en el macizo mariánico andaluz (1.491.388 hectáreas según datos aportados por el CORINE Land Cover 2018)4, además de una considerable continuidad territorial, particularmente en la franja más septentrional de la provincia de Córdoba, coincidente con la altiplanicie granítica de Los Pedroches (Figura 1). Buena parte de las dehesas de Sierra Morena, sobre todo aquellas localizadas en sectores de pendientes más suaves, han mantenido en lo esencial los viejos equilibrios, gracias fundamentalmente a las primas de la UE (Silva y Ojeda, 1997). Pero tales primas han inducido al mismo tiempo y en cada vez más terrenos adehesados una creciente especialización e intensificación ganadera, de importantes impactos ambientales y paisajísticos en enclaves localizados, como se expondrá con posterioridad.

Otras dehesas, las que ocuparon zonas de más complejo relieve, sufrieron con posterioridad el abandono de su uso ganadero, lo que ha conllevado frecuentemente su matorralización (Lasanta, Álvarez y Gómez-Villar, 2014), todavía en proceso en numerosos sectores. Los nuevos espacios invadidos por el matorral también provinieron -aunque en menor medida- de viejas zonas de cultivo abandonadas. Sea como fuere, tales zonas, caracterizadas en la cartografía ambiental como formaciones de matorral o formaciones arboladas de quercíneas con matorral (Figura 1) y que cuentan con un muy significativo alcance territorial en el conjunto del macizo (529.897 ha las primeras y 1.394 .307 las segundas), han sido reorientadas durante las últimas décadas en su vocación funcional y productiva, principalmente hacia la caza mayor, el otro gran vector del uso agrario actual de la Sierra Morena andaluza, junto al pecuario.

Figura 1. Sierra Morena andaluza: localización, principales agroecosistemas y su relación con los Parques Naturales

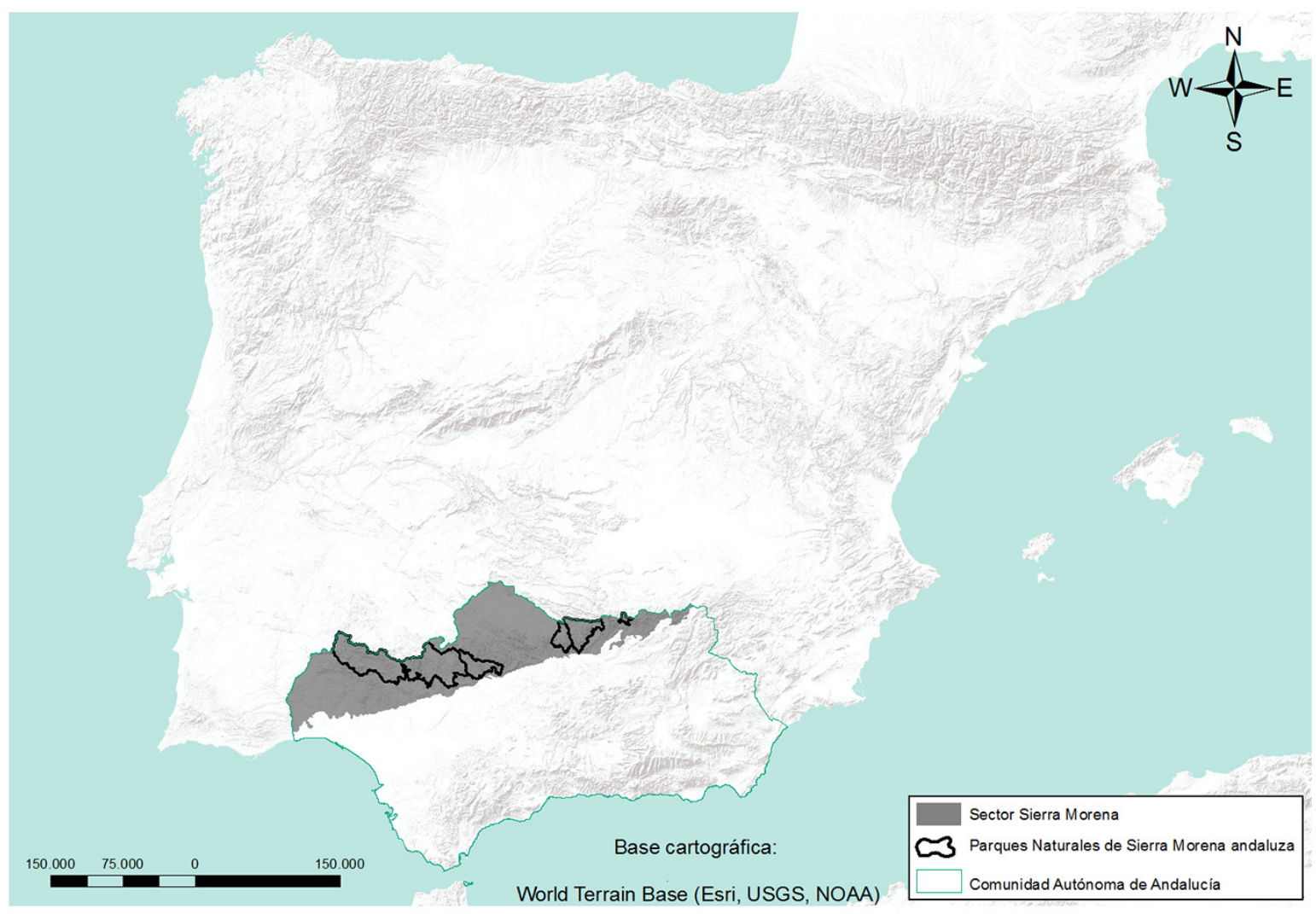

4 Fuente que se ha empleado para la determinación de las superficies totales de los agrosistemas en este apartado, por tratarse de la base cartográfica más actualizada de entre las disponibles. 

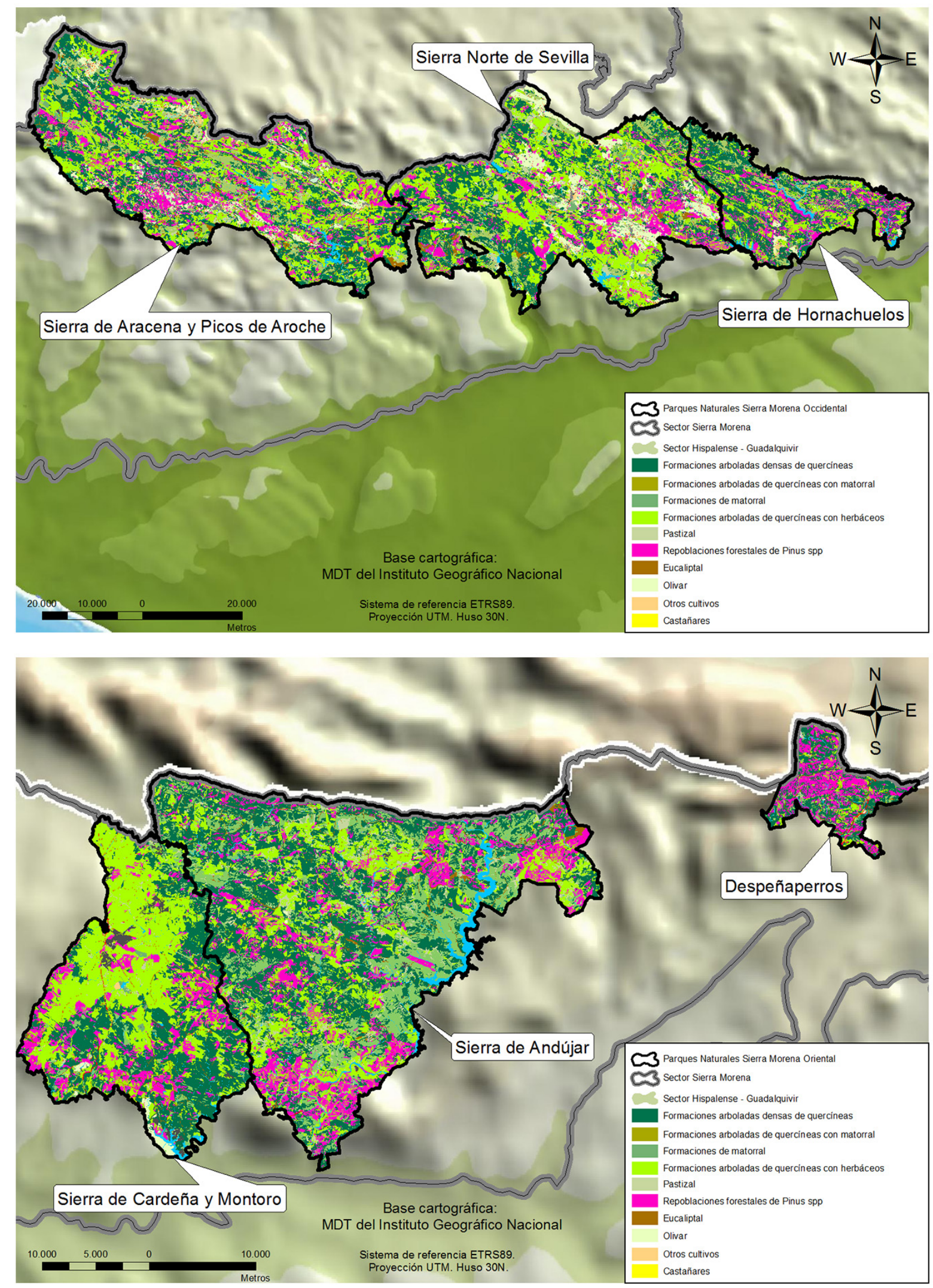

* La partición de Sierra Morena en dos mapas se ha realizado con el objetivo de facilitar la visualización de la distribución de los agrosistemas Fuente: MDT y CORINE LAND COVER 2018. Elaboración propia 
La caza mayor se halla presente asimismo en aquellos sectores de bosque mediterráneo en mejor estado de conservación (caracterizados en la Figura 1 como formaciones arboladas densas de quercineas), dotados asimismo de una importante entidad territorial ( $577.645 \mathrm{ha}$ ), pese a localizarse en aquellas zonas de más difícil accesibilidad por su relieve. La caza y los usos forestales se configuran como realidades funcionales decisivas para la conservación y configuración actual de estas formaciones, que en el caso de aquellas dotadas de mayor continuidad territorial y especialización venatoria han sido acertadamente caracterizadas por Mulero (2013) como representativas del denominado paisaje forestal-cinegético del macizo mariánico.

La expansión de la caza mayor ha hallado asimismo un adecuado sustrato territorial en los sectores ocupados por las repoblaciones forestales pinariegas, que aún gozan de considerable peso en la Sierra Morena andaluza (alcanzando una superficie de 377.973 ha) a partir de la gran expansión repobladora desarrollada entre los años cuarenta y setenta del pasado siglo, sobre terrenos degradados y baldíos en su mayoría y con una motivación tanto protectora - de carácter hidrológico-forestal- como productora —de carácter maderero, sobre todo- (Sánchez, 2009). La compatibilización entre el uso cinegético, forestal (de escasa relevancia) y los tratamientos silvícolas de mejora forestal (en aras de la evolución hacia formaciones de bosque mediterráneo más maduras y estables) resulta hoy día una constante.

Junto a las repoblaciones de coníferas, se detectan igualmente formaciones que pueden ser conceptualizadas como cultivos forestales. No obstante, en este caso cabe realizar una distinción clave. Deben referirse, por una parte, aquellas plantaciones recientes, y carácter masivo e impactante (y por ello de difícil conceptuación como agroecosistemas), como es el caso de los eucaliptales, que en la Sierra Morena occidental ocuparon desde los años centrales del pasado siglo la práctica totalidad de tierras más pobres y marginales, alcanzando una expansión actual de 66.300 ha. Y, por otra, aquellos cultivos de carácter histórico y adecuada adaptación al medio, entre los que los castañares constituyen el mayor exponente, pese a hallarse reducidos en su ocupación a los enclaves más húmedos y frescos de la mitad oeste del macizo (ocupando una superficie de $5.917 \mathrm{ha}$ ).

Este sintético recorrido por los grandes agroecosistemas de la Sierra Morena andaluza no puede obviar la presencia asimismo de cultivos agrícolas. Destaca el gran predominio del olivar, que alcanza una importante continuidad territorial en los sectores sevillano, cordobés y, sobre todo, jiennense de la Sierra Morena, ocupando una superficie total de 249.066 ha; se trata de una pieza fundamental del paisaje del macizo y de la socioeconomía de muchos de sus municipios. Al margen de él, otros cultivos, de histórica presencia en Sierra Morena, hoy se ciñen casi en exclusiva a restos de ruedos en el entorno de numerosos núcleos de población, así como a vestigios de cultivos de mayor extensión pretérita, como es el caso de algunas manchas de viñedos en la Sierra Morena de Sevilla. Una presencia algo más significativa alcanzan los cultivos herbáceos, si bien ceñida casi en exclusiva a sectores de pendientes suaves en el extremo septentrional del espacio mariánico andaluz, principalmente en su sector cordobés.

Muchos de estos agrosistemas han sido objeto de reconocimiento y protección durante las últimas décadas en virtud de sus valores ambientales, ecológicos y paisajísticos. Este proceso de institucionalización (Ojeda y Silva, 2002) ha supuesto un hito de indudable significación en la continua dinámica evolutiva de tales paisajes y los usos agrarios que los sustentan. Al análisis específico de los fundamentos y claves de dicho proceso — tanto de índole geográfica como planificadora— se dedican las páginas que siguen.

\subsection{La disparidad de criterios para la protección de los agrosistemas}

En consonancia con la gran expansión de los espacios protegidos durante las últimas décadas (Naughton-Treves et al., 2005), los terrenos de mayor valor ambiental y paisajístico de la Sierra Morena andaluza han sido sometidos a protección desde finales del siglo XX, resultando clave al respecto el año de 1989. Al margen del reconocimiento otorgado — bajo diversas figuras protectoras - a enclaves de modesta extensión, debe destacarse la protección de amplias porciones territoriales, de nítida dinámica agraria, bajo la figura de Parque Natural (Mulero, 2001; Garzón, 2016). Como muestra del alcance del fenómeno, 577.476 hectáreas se hallan protegidas, de las que un porcentaje mayoritario — 545.215 hectáreas - lo son por los seis parques naturales declarados ${ }^{5}$.

\footnotetext{
5 Según datos aportados por la Consejería de Agricultura, Ganadería, Pesca y Desarrollo Sostenible de la Junta de Andalucía (en la web www.juntadeandalucia.es/medioambiente), en tanto que órgano gestor de la Red de Espacios Naturales Protegidos de Andalucía (RENPA).
} 
El criterio general respecto de la protección de los agrosistemas y formaciones vegetales fue la exclusión de aquellas que implicaban un mayor grado de artificialización y dotadas por ello de un menor valor ambiental; fue el caso de las principales bandas olivareras, las manchas septentrionales de cultivos herbáceos y las zonas dominadas por repoblaciones y plantaciones forestales (Figura 1). No obstante, desde una aproximación más detallada se aprecia una clara disparidad entre los seis parques, con dos modelos reconocibles, que se hallan en correspondencia con la propia divergencia de la Sierra Morena andaluza en la organización espacial de sus agrosistemas. De este modo, la mayor diversidad de sistemas agrarios en su mitad occidental se acompaña de la configuración de dos parques (Sierra de Aracena y Picos de Aroche, y Sierra Norte de Sevilla) de gran extensión — superior a 150.000 hectáreas - y que aglutinan una gran complejidad agraria y paisajística. Frente a ello, el predominio y continuidad de ciertos agrosistemas en su mitad oriental tiene su correlato en el diseño de unos parques de mediana extensión (Sierra de Hornachuelos y Sierra de Cardeña y Montoro, en Córdoba, y Sierra de Andújar y Despeñaperros, en Jaén) y mayor homogeneidad en su estructura territorial y paisajística.

Los dos grandes parques occidentales, coincidentes en lo esencial con ámbitos comarcales de fuerte impronta histórica (Ojeda y Silva, 2002), se singularizan por su mayor grado de humanización directa y las múltiples formas de utilización de la tierra. Conviven aquí variados agrosistemas, combinados en fragmentos territoriales de pequeña o mediana extensión que definen un marcado mosaicismo paisajístico, más acusado en todo caso más al oeste, en la Sierra Morena onubense (Figura 2). Resultan relativamente escasos los vestigios de bosque denso, hallándose por lo general la cubierta forestal originaria profundamente transformada. Esta se identifica tanto con las dehesas de uso ganadero dominante, distribuidas en numerosas manchas salpicadas en las áreas de relieve más favorable, así como con las dehesas matorralizadas, de presencia creciente en sectores de relieve más quebrado, constituyéndose como los ámbitos principales del pujante uso cinegético. Pero quizá el exponente más claro de la diversidad agrosistémica de estos parques - y del criterio de laxitud y multifuncionalidad seguido en su delimitación — radica en el peso asumido por los cultivos, excluidos con carácter general de los límites de los parques cordobeses y jiennenses. Sobresale la presencia del olivar, en bandas de relativa continuidad ocupando laderas de pendientes suaves o moderadas. Pero, junto a él, se hallan presentes otras zonas de cultivos que, pese a su modestia superficial, conforman agrosistemas muy representativos, de gran cualificación pero sujetos hoy en buena medida a procesos de degradación o abandono; es el caso de los viñedos de Cazalla de la Sierra (Sierra Norte), las huertas de la cuenca alta del río Múrtigas (Sierra de Aracena) y, muy especialmente, los ruedos que circundan los numerosos núcleos poblacionales radicados en el interior de los parques (Coronado, 2020). Dicho componente resulta asimismo extensible a los cultivos de carácter forestal, como los castañares, que cuentan con una cierta presencia en zonas elevadas, frescas y húmedas, destacando el sector central de la Sierra de Aracena. Pero, además, la diversidad funcional y paisajística de estas áreas protegidas se completa con una representación no desdeñable de eucaliptales, pese a su carácter impactante.

Figura 2. Dispar configuración agro-territorial: mosaicismo en el entorno del núcleo de Aracena en contraste con la continuidad del bosque mediterráneo en la Sierra de Hornachuelos

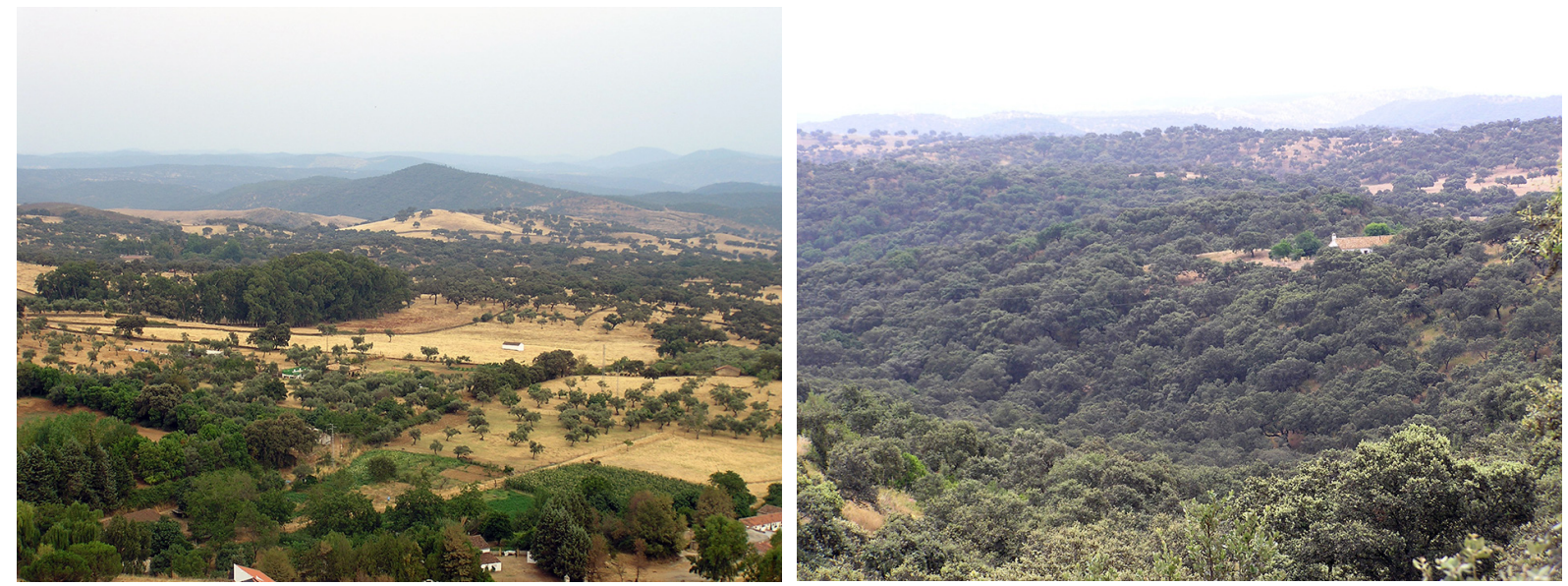

Fotografías de los autores 
Frente a esta realidad, la instrumentación de la protección en los parques naturales de la Sierra Morena centro-oriental siguió criterios distintos, lo que se halla en consonancia con una estructura territorial diferenciada, definida por un menor grado de humanización directa y de diversificación funcional. De este modo, se ha otorgado protección a sectores territoriales bien reconocibles por su alto valor y cualificación ambiental, lo que se vincula a unos usos agrarios muy extensivos (sobre todo ganaderos y cinegéticos), principalmente ligados a una gran propiedad privada preponderante. En cuanto a los agroecosistemas, resultan muy dominantes aquellos de carácter nítidamente forestal, destacando las zonas de bosque mediterráneo maduro (con especial representación en la Sierra de Hornachuelos), las importantes extensiones ocupadas por el matorral (de procedencia diversa: degradación del bosque maduro, dehesas matorralizadas y zonas de cultivo abandonadas) y uso cinegético dominante en la actualidad, así como las repoblaciones de Pinus spp. En el caso de estas últimas, la Figura 1 evidencia con nitidez la aplicación de un criterio muy diferenciado entre parques, constatándose tanto la exclusión de sus límites (en la Sierra de Hornachuelos) como la incorporación de importantes manchas en el interior de los restantes parques, resultando incluso mayoritarias en Despeñaperros. La consideración de una motivación protectora (hidrológico-forestal) para su implantación, la compatibilidad del uso forestal y cinegético, o los criterios —hoy consolidados y en aplicación- de transición de las masas pinariegas hacia formaciones de bosque mediterráneo explican la inclusión de muchas de estas masas dentro del perímetro de los parques (Sánchez, 2009), si bien resulta evidente la ausencia de un criterio unívoco por parte de la Administración ambiental. En el caso de las dehesas, se ha otorgado protección principalmente a aquellos espacios adehesados contiguos a las zonas boscosas y sustentadores de un uso mixto ganadero-cinegético, excluyendo con carácter bastante general las dehesas más estrictamente ganaderas, como las radicadas al sureste del Parque Natural Sierra de Andújar y en el gran continuum adehesado localizado de la comarca de Los Pedroches (Figura 3).

Figura 3. Disparidad en la evolución de los agrosistemas: consolidación de la dehesa ganadera (Los Pedroches, norte de Córdoba) frente a dehesa sujeta a matorralización (Parque Natural Sierra de Andújar)
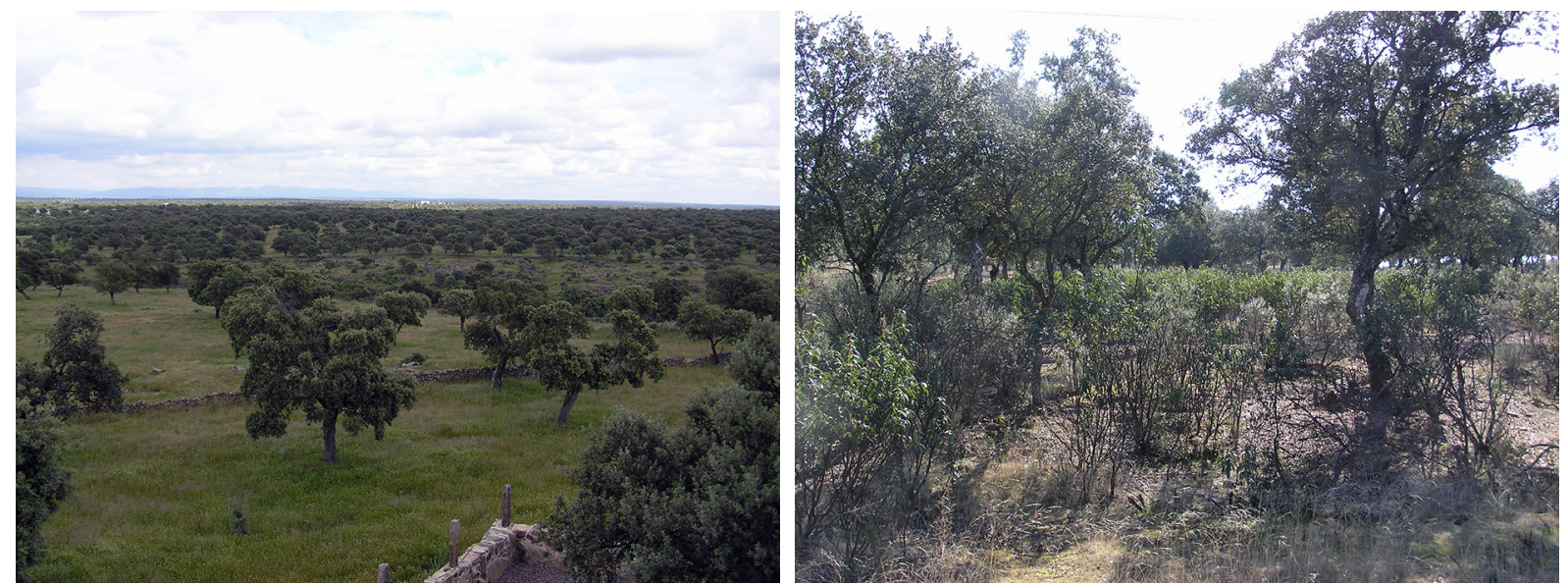

Fotografías de los autores

\section{4. ¿Una efectiva ordenación de los usos agrarios?: la aportación de la planificación y claves de la evolución reciente}

Considerando la disparidad agrosistémica patente entre parques naturales, se abordan los criterios de ordenación y gestión de los usos y paisajes agrarios desde los espacios protegidos y su incidencia en la evolución registrada por ellos.

Para regular su ordenación, los parques naturales andaluces cuentan, al igual que el resto de los parques españoles ${ }^{6}$, con dos instrumentos básicos de planificación (PORN y PRUG), que en su mayor parte fueron aprobados en el año 1994 y renovados en 2003/2004². Ambos incorporan una ordenación de carácter

6 Según lo establecido en la Ley 42/2007, de 13 de diciembre, del Patrimonio Natural y de la Biodiversidad.

7 Los PORN cuentan con una vigencia indefinida (aunque pueden renovarse cuando así se estime conveniente por la instancia administrativa responsable de los parques naturales), mientras que los PRUG — cuya vigencia es de ocho años— fueron en su práctica totalidad prorrogados para un periodo de otros cuatro años mediante diversas Órdenes promulgadas durante los años 2011 y 2012 , sin que hasta la fecha se hayan aprobado los nuevos documentos (www.juntadeandalucia.es/medioambiente). 
funcional, centrada en la regulación de usos y actividades. La ordenación se caracterizó inicialmente por una cierta confusión entre instrumentos, superada tras la dotación planificadora de 2003/2004; desde entonces los PORN definen la regulación básica de usos y actividades (permitidas, prohibidas y autorizables), mientras que los PRUG contienen la regulación específica (condiciones) de los usos permitidos y autorizables.

La regulación aportada por los PORN y PRUG se plantea con el objetivo primordial de conservación de los valores naturales y paisajísticos justificativos de la declaración de los parques, si bien de manera compatible con las dinámicas funcionales - esencialmente agrarias - explicativas de tales valores (López, 2002). La ordenación de los usos agrarios se torna, pues, como un aspecto esencial de la planificación ambiental, como se observa a través de sus contenidos clave: objetivos, zonificación y determinaciones. Se trata, por tanto, de una regulación no muy restrictiva, con aportaciones destacables para la preservación y recuperación de los agroecosistemas, pero también con insuficiencias, referentes sobre todo al reconocimiento de la riqueza agrosistémica y paisajística de los territorios protegidos así como a la necesidad de una mayor concreción y operatividad frente a ciertas dinámicas o amenazas específicas hoy patentes en ellos.

\subsubsection{Objetivos}

En efecto, la relevancia agraria de Sierra Morena y la multifuncionalidad inherente al concepto de Parque Natural se trasluce desde la propia definición de los objetivos de los planes. Con todo, la formulación de los objetivos ha resultado bastante superficial, carente del grado de adaptación y concreción necesario en función de la especificidad y complejidad de cada territorio protegido. Declaraciones programáticas del tenor de "garantizar la conservación y restauración de la cubierta vegetal como elemento esencial para la protección de los suelos frente a la erosión" o "promover un uso económico y social compatible con la conservación de los recursos naturales" (Consejería de Medio Ambiente, 2003/2004) han resultado comunes. Tan solo los objetivos específicos recopilados en los PRUG (Tabla 2) se han planteado con un mayor nivel de concreción que, pese a resultar un tanto insuficiente, sí al menos parecían apuntar a las prioridades de ordenación y gestión de los usos y paisajes agrarios en las diferentes áreas protegidas.

Tabla 2. Objetivos específicos relativos a usos y paisajes agrarios formulados en los PRUG de los parques naturales de la Sierra Morena andaluza

\begin{tabular}{|c|c|}
\hline Parque Natural & Elementos de especificidad en los objetivos de los PRUG \\
\hline $\begin{array}{l}\text { Sierra de Aracena } \\
\text { y Picos de Aroche }\end{array}$ & $\begin{array}{l}\text { - Conservar y mejorar los pastizales de las zonas de dehesa. } \\
\text { - Conservar los castañares como cultivo característico del espacio. } \\
\text { - Reducir progresivamente la superficie de eucaliptales. } \\
\text { - Recuperar las zonas agrícolas con cultivos abandonados o marginales, promoviendo su tránsito hacia } \\
\text { una agricultura ecológica o formaciones forestales. } \\
\text { - Establecer mecanismos para controlar las poblaciones de especies cinegéticas. }\end{array}$ \\
\hline Sierra Norte & $\begin{array}{l}\text { - Sustituir progresivamente la superficie de eucaliptales por formaciones forestales autóctonas maduras } \\
\text { acordes con la potencialidad del ecosistema. } \\
\text { - Conservar y regenerar las áreas de matorral noble. } \\
\text { - Recuperar las zonas agrícolas con cultivos abandonados o marginales, promoviendo su tránsito hacia } \\
\text { una agricultura ecológica o formaciones forestales. } \\
\text { - Minimizar las afecciones ambientales negativas de las explotaciones ganaderas intensivas y extensivas. }\end{array}$ \\
\hline $\begin{array}{c}\text { Sierra de } \\
\text { Hornachuelos }\end{array}$ & $\begin{array}{l}\text { - Favorecer la regeneración de formaciones de matorral y la mejora de pastizales. } \\
\text { - Minimizar la incidencia de la superpoblación de individuos en la pureza genética de las especies } \\
\text { cinegéticas. } \\
\text { - Fomentar la aplicación de técnicas agropecuarias que no supongan el deterioro de los recursos naturales. }\end{array}$ \\
\hline $\begin{array}{l}\text { Sierra de Cardeña } \\
\text { y Montoro }\end{array}$ & $\begin{array}{l}\text { - Conservar y mantener los pastizales de las zonas de dehesa. } \\
\text { - Conservar, mantener y proteger el regenerado natural frente a la influencia del ganado en las dehesas } \\
\text { puras o mixtas de encina y/o alcornoque. } \\
\text { - Promover la aplicación de técnicas agropecuarias que no supongan el deterioro de ningún otro recurso, } \\
\text { especialmente el suelo. } \\
\text { - Minimizar la incidencia de la superpoblación de individuos de especies cinegéticas sobre sus } \\
\text { poblaciones. }\end{array}$ \\
\hline Sierra de Andújar & - Ídem al anterior \\
\hline Despeñaperros & $\begin{array}{l}\text { - Conservar, mantener y asegurar el regenerado natural frente a la influencia de los herbívoros silvestres. } \\
\text { - Conservar y mejorar los pastizales }\end{array}$ \\
\hline
\end{tabular}

Fuente: Consejería de Medio Ambiente (2003/2004). Elaboración propia 


\subsubsection{Zonificación}

En cuanto a la zonificación, su carácter necesariamente sintético (Martínez y Martín, 2003) ha tenido su reflejo, en los parques naturales andaluces, en la definición de tres tipos básicos de zonas según su valor ambiental (zonas A o de Reserva, B o de Regulación Especial, y C o de Regulación Común), de incidencia directa en la regulación de usos y actividades. De este modo, en las zonas A — de valor natural excepcional- pueden desarrollarse ciertos usos agrarios, pero muy extensivos y supeditados al objetivo primordial de conservación; las Zonas B —de valor ambiental alto- sustentan aprovechamientos compatibles con la conservación; las Zonas C —de valor ambiental medio o bajo— se corresponden con las zonas más transformadas, que en términos agrarios se identifican en general con cultivos agrícolas y plantaciones de eucalipto.

Sin embargo, dicha sistematización de la zonificación no debe conllevar una excesiva simplificación, que se traduzca en la no captación de la riqueza y diversidad de los territorios sujetos a protección. En este sentido, la zonificación establecida en los PORN analizados apenas ha implementado una concreción a partir de las tres zonas básicas, que permitiese definir subzonas coincidentes con los principales agroecosistemas, a las que aplicar criterios de ordenación específicos. Por el contrario, la zonificación se ha ceñido en lo esencial al nivel básico, donde se ha hecho patente el gran predominio de las Zonas B, que por ello han concernido a agrosistemas y paisajes muy dispares (que han abarcado desde formaciones densas de quercíneas, dehesas, cultivos forestales tradicionales e incluso espacios de repoblación), en una praxis simplificadora de especial incidencia en aquellos parques de mayor complejidad como los de Sierra Morena occidental (Figura 4).

Figura 4. Simplificación patente en la zonificación de los Parques Naturales Sierra de Aracena y Picos de Aroche y Sierra de Andújar (PORN de 2003)
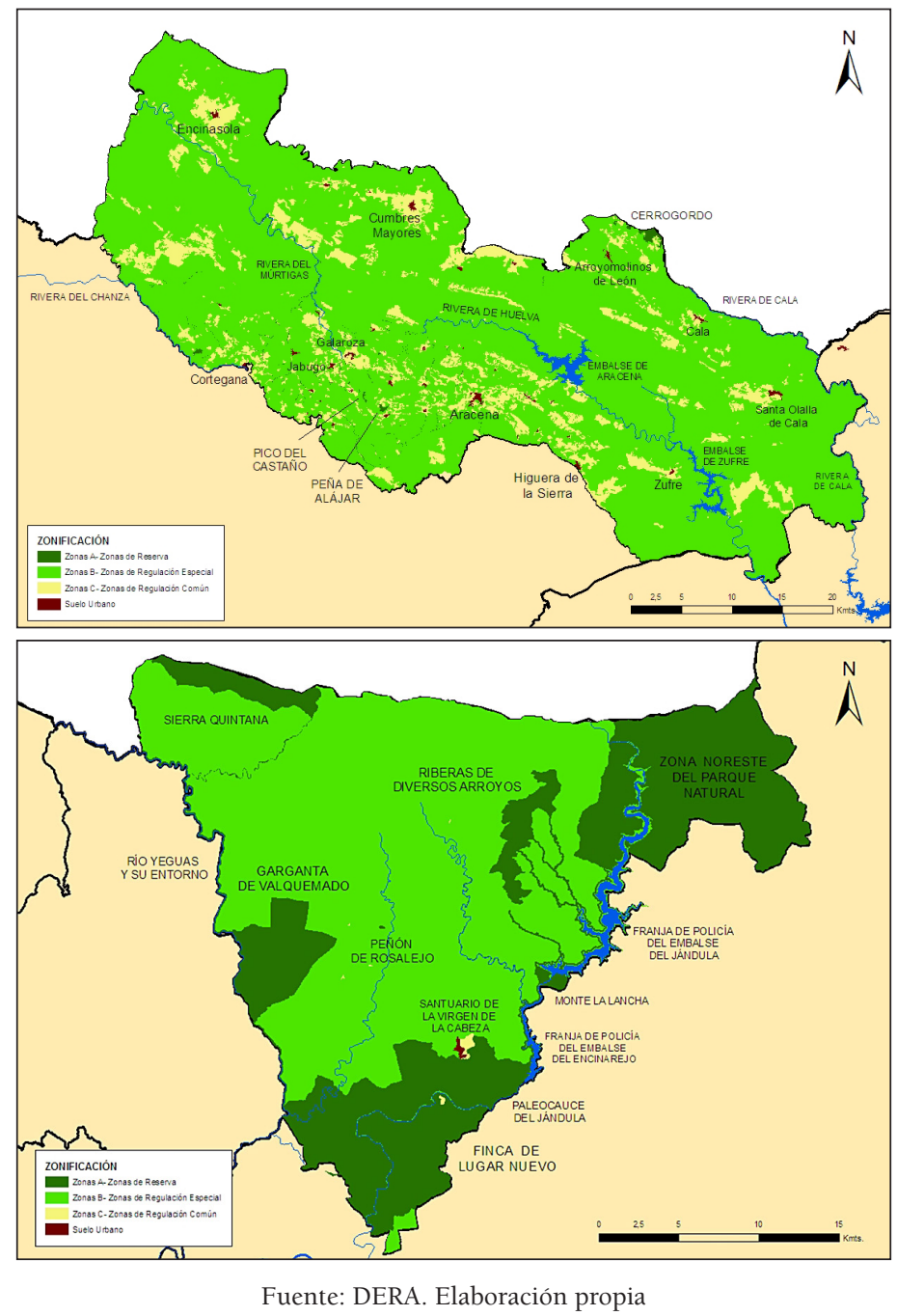


\subsubsection{Determinaciones de aplicación directa}

Las limitaciones de los PORN y PRUG se han hecho asimismo patentes en el caso de su contenido sustantivo, es decir, de aquellas determinaciones - tanto de carácter proactivo como normativo- de aplicación directa sobre los territorios protegidos.

Es el caso, muy en particular, de las medidas o acciones de fomento de los usos y paisajes agrarios, ceñidas de hecho a las líneas de actuación de los PRUG, a las que se ha dotado de un carácter meramente indicativo y, por ello, de nula trascendencia efectiva ${ }^{8}$.

La debilidad de tales determinaciones contrasta con la profusión de la normativa de los PORN y PRUG. No obstante, dicha regulación, planteada en pro de la compatibilización de la actividad agraria con la conservación y recuperación de la cubierta vegetal autóctona (en especial el bosque mediterráneo), ha evidenciado una clara laxitud con respecto a las normativas sectoriales de aplicación a escala española y andaluza.

Así lo prueba, primeramente, el que sean escasas las prohibiciones específicas contenidas en las normas generales de los PORN, limitadas a un reducido elenco de praxis consideradas como especialmente impactantes. La principal limitación contenida en los planes se halla, de hecho, en la normativa particular (asociada a la zonificación). Se trata de la regulación sobre los cambios de usos del suelo. A este respecto, sobre la base de la definición de un régimen general para la totalidad del medio natural andaluz, que establecía la necesidad de autorización administrativa para todo cambio de uso de los terrenos forestales para cultivos agrícolas u otros forestales (Ley 2/1992, de 15 de junio, Forestal de Andalucía, artículo 69.1), los parques naturales de Sierra Morena han dispuesto de un régimen propio y común, de notable coherencia global:

- En las zonas A se calificaba como incompatible cualquier cambio de uso del suelo, en función de la fragilidad ecológica y paisajística de estas zonas.

- En las zonas B se estipulaba una norma genérica orientada a salvaguardar el bosque mediterráneo en cualquiera de sus manifestaciones - de todo tipo de merma. Se trata de la incompatibilidad de la eliminación de especies arbóreas o arbustivas autóctonas, a excepción de los tratamientos silvícolas de conservación y mejora de la vegetación. Pero, a la integridad del bosque mediterráneo se añadía, en un sentido más general, la pretensión de conservar el carácter forestal de los terrenos incluidos en las zonas B. En esta línea se situaba la prohibición directa - en la Sierra de Aracena y Picos de Aroche y Sierra Norte - delcambio de uso forestal a agrícola. Por su parte, en los parques cordobeses y jiennenses dicha disposición se reemplazaba por otra (incompatibilidad de la roturación de terrenos forestales con fines agrícolas) que, además de incluir a la anterior, respondía a las posibles presiones de esta índole en las dehesas y pastizales de estos territorios protegidos 9 .

- Por último, en las zonas de Regulación Común (zonas C), su escaso valor ecológico general explica la carencia de disposiciones en un sentido restrictivo, limitándose los PORN a especificar que se consideraría incompatible cualquier actuación para la que así se determinase en el correspondiente procedimiento de autorización. Con todo, el carácter residual de muchas de las manchas de cultivos aún presentes en las zonas $C$ llevó al planificador a incluir una disposición con un carácter esencialmente orientativo. Se trató de la calificación como actividad compatible de "la transformación de los cultivos hacia el uso forestal con especies autóctonas", hecho que se hallaba en plena sintonía con la esencial vocación forestal del macizo.

La regulación de los cambios de uso constituye una aportación muy interesante de la planificación, sobre todo en el caso de las zonas B, preponderantes superficialmente en los parques naturales. Dicha regulación se ve además complementada por la normativa general de los PORN y PRUG, relativa a la ordenación tanto de los usos agrarios (ver epígrafe siguiente) como de las labores sobre el terreno que posibilitan su desarrollo.

A este respecto, se otorga una especial relevancia a las disposiciones orientadas a prevenir el impacto de los trabajos culturales de carácter tradicional sobre la vegetación mediterránea. En efecto, los PORN y PRUG de 2003/2004 incorporaron un régimen protector propio para el desarrollo de tales trabajos,

8 Acciones o medidas de fomento de los usos agrarios se han incorporado asimismo a otras iniciativas planificadoras, como es el caso de los Planes de Desarrollo Sostenible (PDS) de los parques naturales, que en todo caso han venido adoleciendo asimismo de una notable inoperatividad en lo relativo al manejo agrario sobre el terreno (Mulero y Garzón, 2005; Garzón y Ramírez, 2016).

9 De hecho, la normativa particular de los dos parques naturales de la Sierra Morena cordobesa especificaba la compatibilidad -en zonas B- de "la siembra de especies forrajeras para su consumo a diente siempre que no supusiesen alteración de los prados naturales ni remoción del suelo". 
complementario a lo dispuesto en la legislación forestal (Tabla 3) ${ }^{10}$. Los condicionantes establecidos (para la concesión de autorización administrativa) apuntaban a una ejecución selectiva a nivel de especies y formaciones, así como en cuanto a la ineludible conservación de la capa edáfica fértil.

Tabla 3. Regulación específica de trabajos forestales de orientación agraria contenida en los PORN y PRUG de 2003/2004 de los parques naturales de la Sierra Morena andaluza

\begin{tabular}{|c|c|}
\hline Trabajo forestal & Regulación específica \\
\hline Desbroce o roza de matorral & $\begin{array}{l}\text { - Solo pueden realizarse para prevención de incendios, favorecer la regeneración de } \\
\text { formaciones arbóreas o pastizales, y en ruedos de descorche, debiéndose respetar una } \\
\text { franja de } 5 \mathrm{~m} \text {. en las márgenes de los cursos de agua } \\
\text { - Deben respetar el regenerado de especies arbóreas, las especies arbustivas que hubiesen } \\
\text { alcanzado porte arbóreo, y, de manera general, los ejemplares de especies forestales o de } \\
\text { matorral noble mediterráneo presentes } \\
\text { - Con remoción de suelo, se prohíben en pendientes superiores al 20\% }\end{array}$ \\
\hline $\begin{array}{l}\text { Laboreo en dehesas } \\
\text { (para plantas forrajeras o } \\
\text { cultivos herbáceos) }\end{array}$ & $\begin{array}{l}\text { - Se limita la profundidad máxima del laboreo a } 30 \text { centímetros } \\
\text { - Se ha de tener en cuenta la aplicación del ciclo tradicional de la dehesa para fomentar la } \\
\text { matorralización y el aporte de materia orgánica al suelo }\end{array}$ \\
\hline $\begin{array}{l}\text { Repoblación y/o plantación } \\
\text { forestal }\end{array}$ & $\begin{array}{l}\text { - Se han de conservar los enclaves de vegetación arbórea y matorral noble mediterráneo } \\
\text { existentes con capacidad de regeneración natural. } \\
\text { - Se prohíben los nuevos aterrazamientos en labores de preparación del suelo }\end{array}$ \\
\hline Corta de árboles & $\begin{array}{l}\text { - No se permite en los siguientes supuestos: que contuviesen nidos de rapaces u otras } \\
\text { especies de aves protegidas; que fuesen excepcionales por tener alguna especial } \\
\text { significación natural, cultural o histórica; que estuviesen en lugares de pendiente } \\
\text { superior al } 50 \% \text { y no tuviesen asegurada su sustitución o pudiesen causar graves daños } \\
\text { en el arrastre; que se situasen en las márgenes de ríos y arroyos, en la franja de cinco } \\
\text { metros correspondientes a la zona de servidumbre }\end{array}$ \\
\hline $\begin{array}{l}\text { Tratamientos silvícolas } \\
\text { (sobre la vegetación arbórea) }\end{array}$ & $\begin{array}{l}\text { - Se realizarán de forma selectiva, evitando toda afección a las especies características del } \\
\text { matorral noble y a individuos o poblaciones de especies endémicas y/o amenazadas }\end{array}$ \\
\hline
\end{tabular}

Fuente: Consejería de Medio Ambiente (2003/2004). Elaboración propia

\subsubsection{Gestión y evolución específica de los usos agrarios}

La planificación ambiental de los parques naturales de Sierra Morena contiene asimismo en su normativa general una regulación de los principales usos agrarios y agrosistemas, que tampoco resulta especialmente restrictiva respecto de lo dispuesto en las legislaciones sectoriales aplicables. De una manera necesariamente sintética, en este epígrafe se aportan las claves fundamentales de esta regulación, así como de su incidencia en la evolución reciente de los principales usos agrarios de los espacios considerados.

\section{A) La caza mayor}

La ordenación de la actividad cinegética (caza mayor, muy dominante en Sierra Morena) se ha hallado decisivamente marcada por la generalización -en los acotados incluidos en el interior de los parques naturales- de los Planes Técnicos de Caza (PTC) ${ }^{11}$, para la regulación de la actividad. Ello, junto a la completa legislación andaluza en la materia ${ }^{12}$, explica que sean pocas las determinaciones específicas de los PORN y PRUG. Estas se han ceñido en lo esencial a lo dispuesto acerca de varias problemáticas singulares patentes en los parques respecto de la caza mayor: la sobrecarga de reses (sobre todo de ciervos, especie cinegética

10 En este caso, era el artículo 96 del Reglamento Forestal Andaluz de 1997 el que extendía la necesidad de autorización administrativa para todas las labores de "corta, quema, arranque o inutilización de las especies arbóreas y arbustivas" enumeradas en su anexo, con la excepción de las "labores de limpieza de matorral en dehesas con pendientes inferiores al 20 \%, siempre que no afectasen a especies incluidas en el Catálogo Andaluz de Flora Silvestre Amenazada". Se estipulaba igualmente la obligatoriedad de la autorización para la "roturación de terrenos forestales y la realización de actuaciones que originasen o pudiesen originar procesos de erosión", señalándose en este caso como excepción "los terrenos forestales adehesados que tradicionalmente hubiesen sido cultivados y cuya pendiente fuese inferior al $20 \%$ ".

11 Instrumento ya previsto en el Capítulo III del Título IV de la Ley estatal 4/1989, de 27 de marzo, de Conservación de los Espacios Naturales y la Flora y Fauna Silvestres (hoy derogada por la Ley 42/2007, de 13 de diciembre, del Patrimonio Natural y la Biodiversidad), en el que se disponía la obligatoriedad de que "todo aprovechamiento cinegético en terrenos acotados al efecto debiese hacerse, por el titular del derecho, de forma adecuada y conforme al Plan Técnico justificativo de la cuantía y modalidades de las capturas a realizar, con el fin de fomentar y proteger la riqueza cinegética" (artículo 33.3).

12 Cuyo hito fundamental lo constituye hoy día el Decreto 126/2017, de 25 de julio, por el que se aprueba el Reglamento de Ordenación de la Caza en Andalucía (BOJA núm. 149, de 04/08/2017). 
por excelencia en el macizo de Sierra Morena), el recurrente desequilibrio poblacional (en favor de las hembras), y la gran expansión de los cercados cinegéticos.

En el caso de los cerramientos cinegéticos, su importante impacto ecológico (al limitar la movilidad de las reses) explica dos determinaciones incluidas en la planificación ambiental de los parques naturales. Por una parte, la incompatibilidad del establecimiento de nuevos cercados en aquellos sectores clasificados como de máxima protección (zonas A), de significativa representación en parques de gran peso cinegético como Sierra de Hornachuelos o Sierra de Andújar; y, por otra, la potestad de declarar obligatorias actuaciones de control poblacional (por ejemplo, descastes o caza selectiva en cotos con un excesivo número de ciervas) y de renovación genética (que se llevaría a efecto mediante la introducción de hembras, que además procederían, cuando fuese posible, de capturas realizadas en cotos cercanos donde se detectase desequilibrio poblacional).

Sea como fuere, las problemáticas referidas evidencian bien a las claras que la protección no ha conllevado una limitación y merma del uso cinegético, sino, antes, al contrario, una consolidación y desarrollo desde la declaración de los parques naturales en 1989. Los datos disponibles de diversas variables básicas $^{13}$, como número de jornadas cinegéticas y capturas, que se ejemplifican para el caso del Parque Natural Sierra de Hornachuelos, así lo muestran, pese a la existencia de fluctuaciones interanuales, mayoritariamente explicadas por condicionantes meteorológicos (Figura 5).

Otros datos también evidencian el importante desarrollo de la caza mayor en los parques naturales. Es el caso de la evolución superficial de los principales agrosistemas que sustentadores de la actividad cinegética de calidad (formaciones arboladas densas de quercíneas y formaciones arboladas de quercíneas con matorral), que han visto incrementar su superficie en el interior de los territorios protegidos (Anexo 2).

Figura 5. Evolución del número de jornadas cinegéticas de las principales modalidades de caza mayor y del número de capturas por especies en el Parque Natural Sierra de Hornachuelos
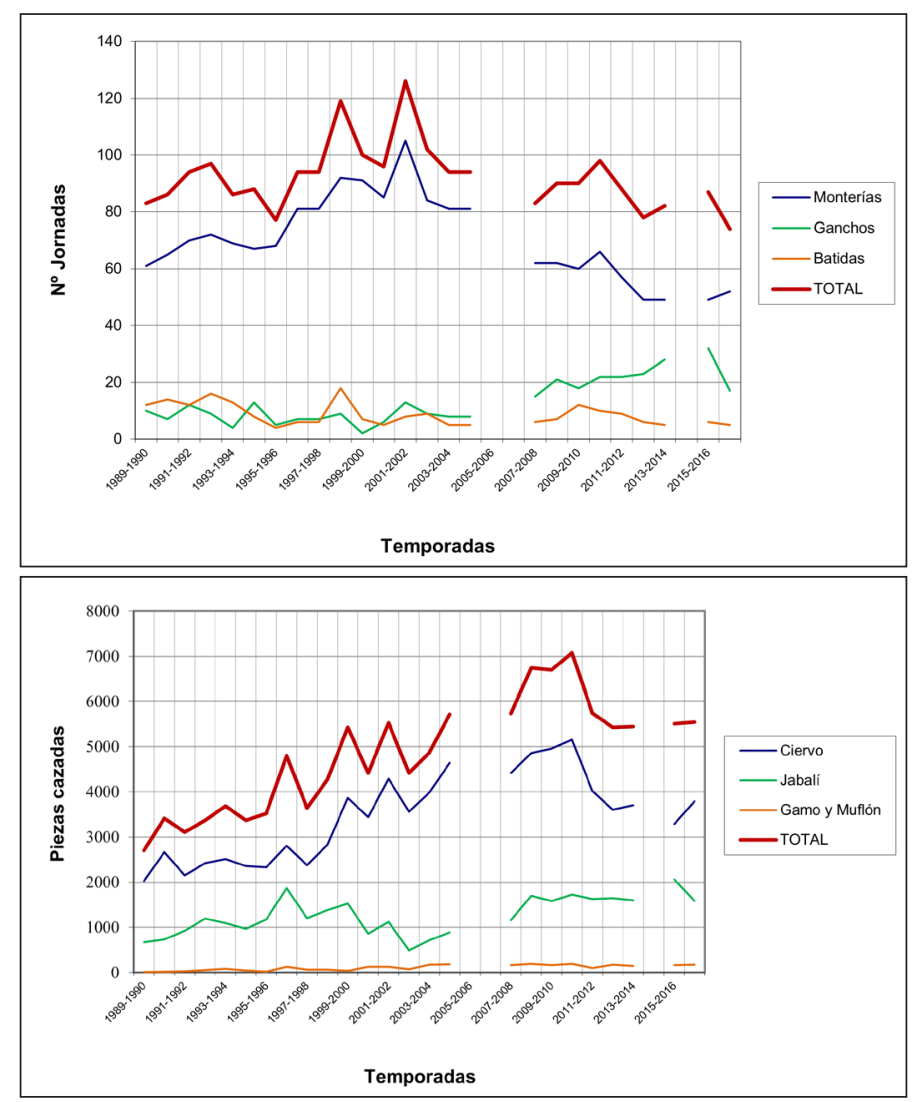

Fuente: Memorias Anuales de Actividades del Parque Natural Sierra de Hornachuelos. Elaboración propia

13 Aportados por las Memorias de Actividades, que presentan diversas lagunas en lo que a la continuidad de la información aportada respecta (como se puede constatar al observar la Figura 5). 


\section{B) La ganadería}

En el caso de la ganadería, segundo gran uso agrario de los parques naturales de Sierra Morena, la normativa contenida en la planificación ambiental evidencia una preocupación clave respecto de su posible impacto sobre los recursos naturales sustentadores.

La disposición fundamental de los PORN establece que la Administración ambiental, en aquellas fincas dedicadas a la ganadería donde se hubiesen detectado problemas severos de sobreexplotación de la vegetación o de erosión del suelo, adoptaría las medidas necesarias para hacer frente a tales problemas, como limitar la carga ganadera, establecer un acotamiento temporal u otras, hasta que se adoptasen medidas correctoras que no pusiesen en riesgo el mantenimiento de estos recursos. Esta determinación básica se ha acompañado de otras disposiciones de sesgo más específico, que reflejaban algunos de los aspectos de conflictividad que han venido afectando al aprovechamiento ganadero.

Una primera muestra ha sido la regulación de la necesaria adecuación del uso ganadero a los recursos disponibles de acuerdo con los restantes aprovechamientos, en particular en lo relativo a la carga que representan tanto el ganado doméstico como las especies de caza mayor. Dicha prevención se limitaba a cuatro de los parques naturales (Sierra Norte, Sierra de Hornachuelos, Sierra de Cardeña y Montoro, y Sierra de Andújar), aquellos más claramente afectados por la creciente compatibilidad cinegético-ganadera.

Una segunda disposición regulaba acerca de los recursos pastables y su necesaria conservación. Se estipulaba que el tiempo de permanencia del ganado en los pastos naturales no debería prolongarse más allá de lo necesario para que consumiese su producción estacional, permitiendo la supervivencia de especies pratenses perennes y la producción de semillas de especies anuales que asegurase la renovación de los pastos. No obstante, en los PRUG de algunos parques (Sierra de Aracena y Picos de Aroche, Sierra de Hornachuelos y Sierra de Cardeña y Montoro, aquellos con mayor implantación de las explotaciones semiextensivas para la cría del ganado porcino) se incorporaba la apostilla "salvo en las cercas necesarias para el manejo tradicional del ganado porcino" (Consejería de Medio Ambiente, 2003/2004), lo que parecía justificar los fuertes impactos de carácter vegetal y edáfico sobre parcelas específicas de los espacios protegidos.

Este aspecto de conflictividad respecto de las parcelas de cría o cebado del porcino se contrapone a la regulación general del uso ganadero en la planificación, de notable interés en su espíritu. Pese a ello, esta normativa se ha singularizado por su inconcreción, al no incorporar variables necesarias como umbrales de sobreexplotación vegetal y deterioro edáfico, cargas ganaderas por especies, o tiempos de permanencia en los pastos.

Pero, además de la inconcreción de la normativa, su aplicación se ha visto dificultada por una casuística particular registrada desde la creación de los parques naturales en Andalucía. A diferencia de la caza y los usos y prácticas de carácter forestal, reguladas directamente desde la Administración ambiental autonómica (que es, a su vez, la entidad gestora de los parques naturales), las actividades ganaderas y agrícolas lo han sido desde la Administración agraria. Se impone, pues, una imprescindible colaboración entre diferentes instancias administrativas, que no siempre se ha dado con la suficiente fluidez. Se ha dificultado así la aplicación de las disposiciones de la planificación ambiental, lo que permite explicar situaciones impactantes en el interior de los espacios protegidos, como por ejemplo episodios evidentes de sobrecarga ganadera en pastizales y dehesas (Figura 6). La reciente unificación registrada en Andalucía entre las administraciones ambiental y autonómica ${ }^{14}$ sin duda puede contribuir a una mejora de la gestión de la ganadería en los parques naturales, aunque esta habría de afrontar diversos retos, entre los que cabe destacar la cuantificación precisa de las cabañas y la carga ganadera, y la aportación de una regulación que defina umbrales precisos de sobrecarga ganadera y limitaciones concretas cuando fuese necesario (Schröder, 2005; Lázaro y Vera, 2009; Silva, 2010). Sin duda la reformulación de la planificación de los parques debe resultar clave en este sentido, pero también podría serlo la definición de una planificación de manejo ganadero para la totalidad de las explotaciones, de manera similar a lo que aportan los PTC para el uso cinegético ${ }^{15}$.

14 Con la creación en 2019 de la Consejería de Agricultura, Ganadería, Pesca y Desarrollo Sostenible.

15 En esta línea, en Andalucía tan solo se contempla en la actualidad la obligatoriedad de que las explotaciones intensivas (con carga ganadera superior a 1,5 UGM por hectárea) cuenten con un Plan de Gestión de Subproductos Ganaderos (PGSG), según lo establecido en el Decreto 14/2006, de 18 de enero, por el que se crea y regula el Registro de Explotaciones Ganaderas de Andalucía. 
Figura 6. Parcela para la cría y cebo del ganado porcino (Sierra de Aracena y Picos de Aroche) y sobrecarga ganadera en explotación extensiva de vacuno (Sierra Norte)
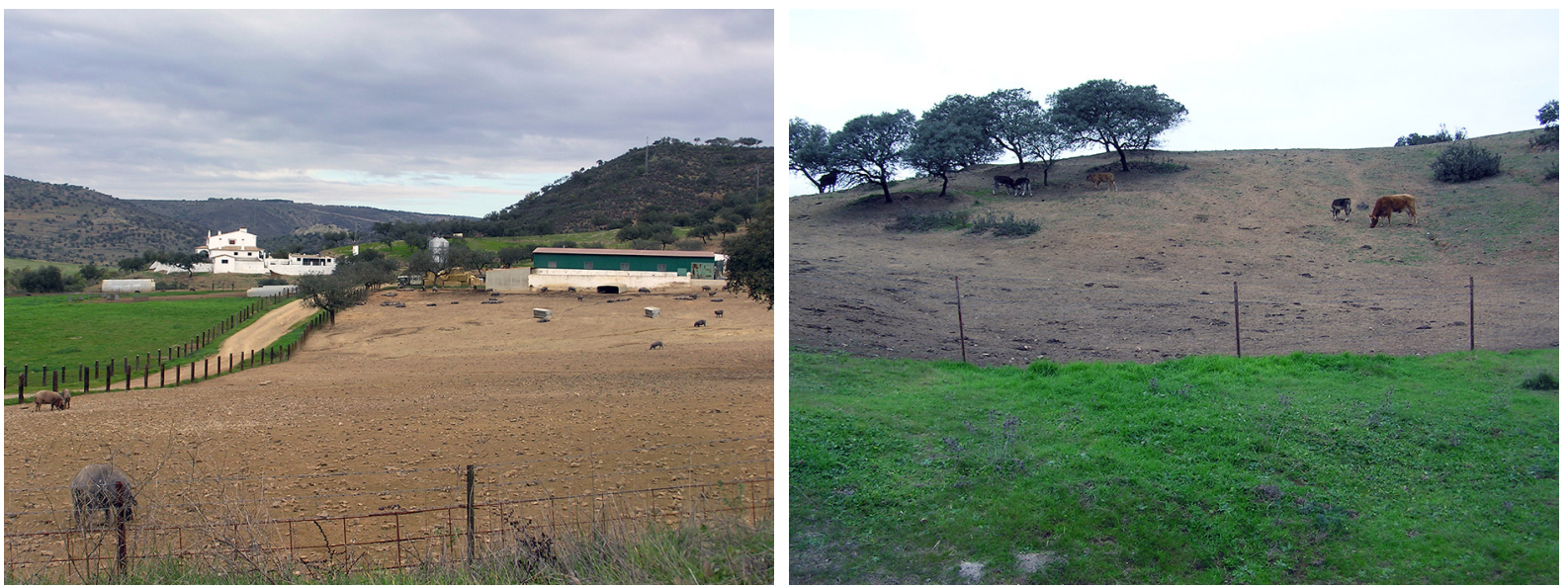

Fotografías de los autores

En todo caso, y de manera similar a lo que se señaló para el uso cinegético, lo expuesto en párrafos anteriores parece apuntar no a una limitación del uso ganadero en los parques naturales, sino antes bien a un mantenimiento e incluso a un reforzamiento. Así parece reflejarse, por ejemplo, en los datos de evolución de las cabañas en los tres parques de mayor peso pecuario, extraídos de los Censos Agrarios, ante la referida ausencia de censos específicos para las explotaciones de los parques naturales (Figura 7).

Figura 7. Evolución de la cabaña ganadera en municipios de los parques naturales Sierra de Aracena y Picos de Aroche, Sierra Norte, y Sierra de Cardeña y Montoro

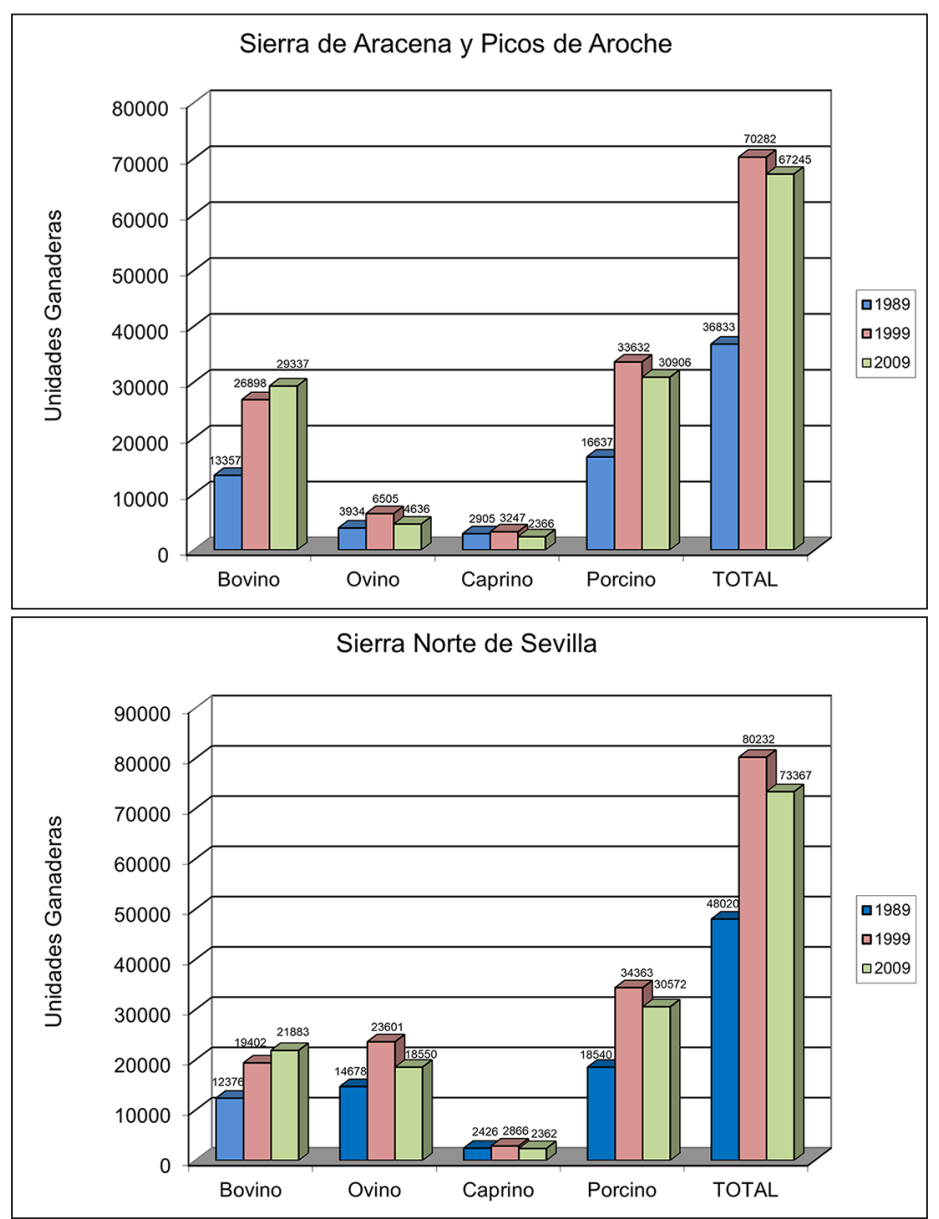




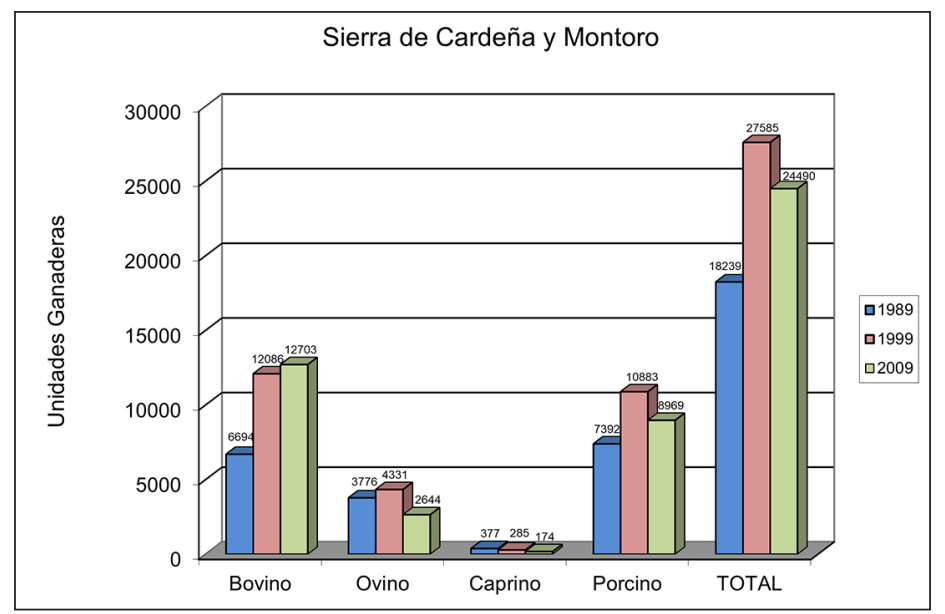

* La utilización de las UG se explica porque era la única medida utilizada para la contabilización ganadera en el Censo Agrario de 1989. No se utiliza el Censo Agrario de 2019 por no haberse publicado en el momento de finalizar este trabajo

Fuente: Censo Agrario de 1989, Censo Agrario de 1999 y Censo Agrario de 2009 (www.ine.es). Elaboración propia

En cuanto a los agrosistemas sutentadores del uso ganadero, la expansión del principal de ellos, la dehesa (formaciones arboladas de quercíneas con herbáceos), pero también de los pastizales (Anexo 2), aunque con importantes impactos ambientales en sectores concretos (no cuantificados, como se señaló), parece ser un fiel reflejo también de esta dinámica apuntada.

Igualmente, la consolidación del importante entramado empresarial vinculado al porcino en la Sierra de Huelva y la pujanza de otras iniciativas — como por ejemplo CorSevilla en la Sierra Norte- parecen apuntar en la misma línea, aunque su tratamiento detallado excedería con mucho los límites de esta aportación.

\section{C) Los cultivos agrícolas}

Los cultivos agrícolas tienen mucha menor relevancia que la caza y la ganadería en los parques naturales de Sierra Morena (Anexo 2). Al margen de las pequeñas manchas de cultivos frutales y hortícolas que aún perduran en ruedos y proximidades de cursos fluviales, y que se destinan principalmente al autoconsumo y mercados locales, tan solo los viñedos del sector central de la Sierra Norte y, de manera más generalizada, el olivar, alcanzan una entidad que pueda considerarse representativa.

En cuanto a su evolución superficial, la estabilización o ligera regresión constatada en el interior de los parques, a diferencia de la expansión registrada en el exterior de ellos (Anexos 1 y 2), se ve decisivamente influida por la planificación ambiental, en concreto por la imposibilidad de expansión de los cultivos por la normativa de cambios de uso vinculada a la zonificación de los parques naturales, expuesta en páginas anteriores.

Junto a esto, la regulación específica de los usos agrícolas en los parques de Sierra Morena se centra fundamentalmente en la prohibición de ciertas praxis especialmente impactantes sobre los recursos sustentadores de la actividad, particularmente el suelo fértil: el laboreo del suelo siguiendo las líneas de máxima pendiente, los aterrazamientos en las labores de preparación del terreno, y la eliminación de los setos o restos de formaciones forestales existentes en terrenos agrícolas. Además de lo anterior, la normativa de los PORN establece la necesidad de autorización para otros usos (como la transformación de las huertas tradicionales o el arranque de cultivos leñosos para instalación de cultivos herbáceos), en la línea de asegurar en lo posible la preservación de cultivos históricos y de alto valor paisajístico.

No obstante, la ordenación ha evidenciado nuevamente claros incumplimientos ante la falta de control sobre el terreno (Figura 8), en lo que también ha influido la casuística de dualidad competencial antes expuesta a propósito de uso ganadero.

La insuficiencia de la ordenación se ha hecho también patente en la ineludible consideración de nuevas realidades, como por ejemplo el creciente adehesamiento de olivares convirtiéndolos en explotaciones mixtas (Figura 8), o la necesaria incorporación de medidas proactivas para garantizar la funcionalización —en aras de la efectiva preservación- de las zonas de cultivo tradicional aún existentes. 
Figura 8. Olivar en pendiente sometido a intensa erosión edáfica y olivar adehesado (Arroyomolinos de León, Parque Natural Sierra de Aracena y Picos de Aroche)
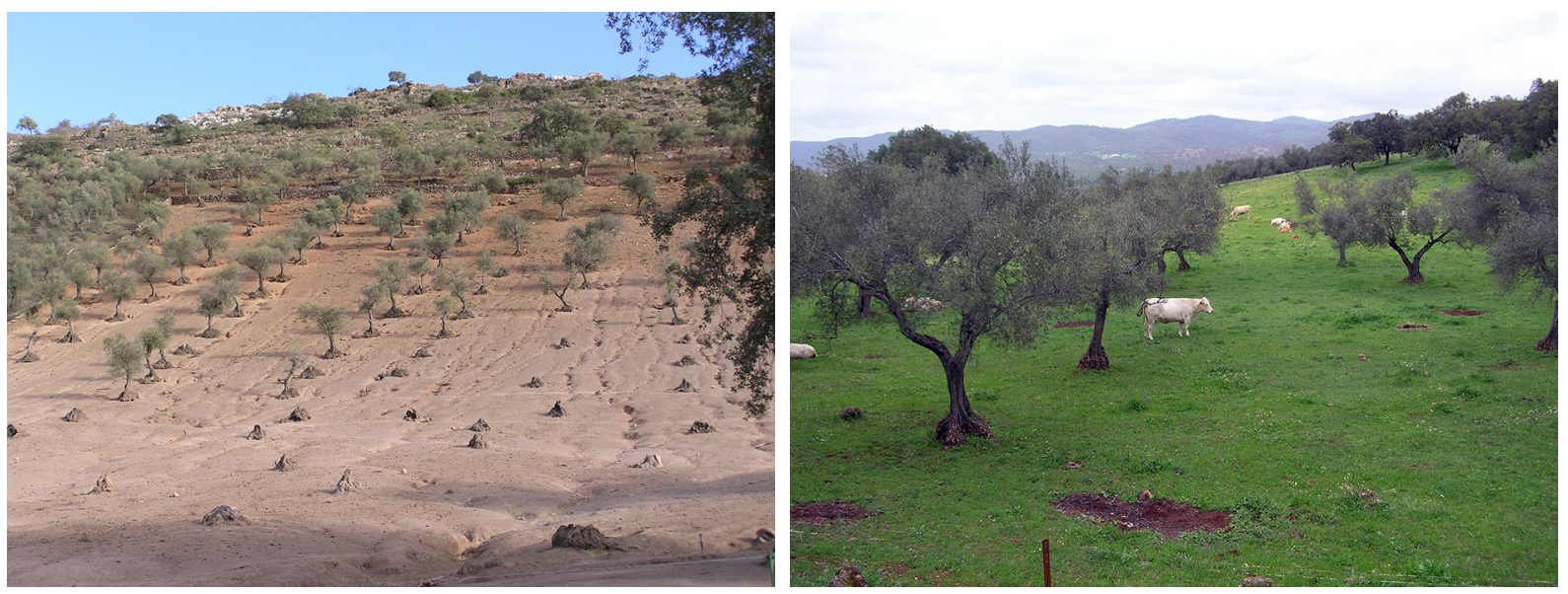

Fotografías de los autores

\section{D) El cultivo del castañar}

La planificación ambiental ha incorporado también una regulación de los cultivos y plantaciones forestales. Entre los de carácter tradicional, estos se ciñen en lo esencial a los castañares que, aunque se extienden por diversos enclaves de Sierra Morena y sus parques naturales, es en el sector central de la Sierra de Aracena donde alcanzan una representación de entidad. La planificación ambiental (PORN y PRUG del Parque Natural Sierra y Picos de Aroche) incorpora una regulación escasa, aunque en ella se reconoce un sesgo protector en pro del mantenimiento de estos agrosistemas tradicionales. Se dispone así la prohibición de la eliminación, arranque o deterioro de antiguos castañares, salvo en caso de renovación controlada, a lo que se añade el requerimiento de autorización para la introducción de nuevas variedades de castaño con fines productivos.

No obstante, los datos de evolución de la superficie de castañar reflejan un claro retroceso durante los últimos lustros (Anexo 2), lo que evidencia una situación problemática que la escasa regulación contenida en la planificación no ha permitido afrontar. La problemática ha afectado a la doble dimensión básica de este agrosistema: el manejo en el campo, y la transformación y comercialización de las producciones.

En cuanto al manejo en el campo, hay que destacar el problema decisivo que ha venido suponiendo la creciente pérdida de rentabilidad para las pequeñas explotaciones castañeras de la Sierra de Aracena (Rubio, 2011). Ello se explica por la conformación de estos castañares, caracterizados por un arbolado envejecido y con escasez de pies polinizadores, lo que repercute en la menguante producción de castañas (desde más de 3.500 tm anuales en los años 90 a cifras inferiores a las 1000 tm durante los últimos años). Además, las variedades cultivadas han resultado poco adaptadas a las demandas del mercado, con lo que el valor en bruto de la castaña ha sido durante los últimos años menor que los costes de producción. La pérdida de rentabilidad ha conducido al abandono o semiabandono de muchas explotaciones (Garzón, 2016).

A todo ello se han añadido las importantes carencias a nivel de manufacturación y comercialización de los productos, de manera que gran parte de la producción castañera se exporta en bruto, sin recibir ningún tipo de labor industrial, ni siquiera de preparación.

Ante esta situación tan problemática, durante los últimos años se ha registrado un reforzamiento de la acción administrativa (principalmente autonómica) en favor del castañar, en el que el papel de la realidad Parque Natural ha resultado de especial importancia. Además de incentivos financieros ${ }^{16}$, que subvencionan las labores de mantenimiento de las explotaciones pero que no abordan las causas de fondo de su pérdida de rentabilidad, el aspecto más destacado y novedoso de la intervención pública ha sido el impulso de la investigación en pro de la posible introducción en la Sierra de Aracena de nuevas variedades de castaño más productivas y resistentes a plagas (posibilidad ya contemplada por el PORN, como se refirió con anterioridad).

16 Cuyo punto de partida vino dado por el Decreto 280/2001, de 26 de diciembre, por el que se establecen las ayudas de la Junta de Andalucía a los sectores agrícola, ganadero y forestal incluidas en el Programa Operativo Integrado Regional de Andalucía para el Desarrollo del Marco Comunitario de Apoyo 2000-2006. En el caso particular del castañar, se ha venido otorgando prioridad a las explotaciones de menor tamaño (con superficie inferior a 30 hectáreas) y localizadas en el interior de áreas protegidas. 
Figura 9. Castañar abandonado y castañar en producción en la Sierra de Aracena
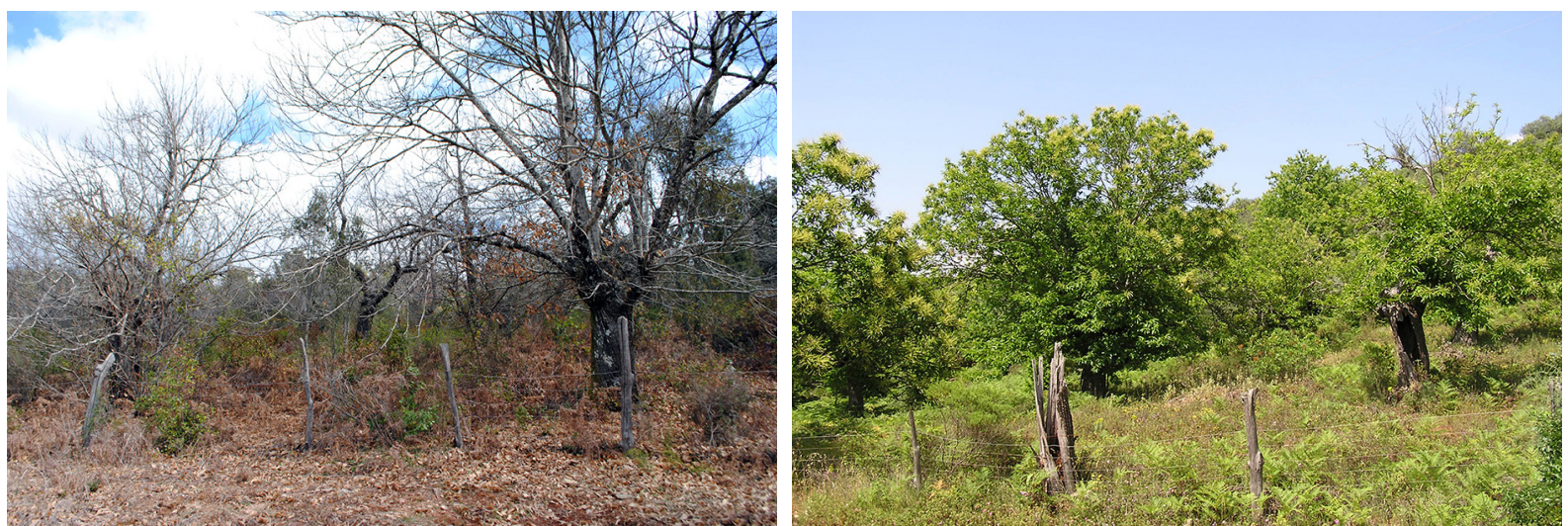

Fotografías de los autores

En esta línea, han sido varios los proyectos pioneros específicamente impulsados en el Parque Natural Sierra de Aracena y Picos de Aroche. Para ello se ha recurrido a la práctica de la polinización cruzada, es decir, cruces de individuos locales con ejemplares de variedades de castaños procedentes de Francia, Alemania, Italia y Galicia, que destacan por su productividad y su calidad. Los primeros resultados obtenidos de los ensayos de polinización parecieron mostrar una buena adaptación de las nuevas variedades a las condiciones ambientales de la Sierra de Aracena, hecho que se manifestó en la rapidez del crecimiento, lo que parece atisbar un panorama algo más halagüeño en un medio plazo. El objetivo último, cuya consecución se encuentra aún en curso, es el de hallar la especie que mejor se adapte a los suelos de la zona, mediante el estudio de parámetros relativos al fruto como el sabor, tamaño, temporalidad o facilidad de pelado, que convirtiese al fruto en más apto para la transformación y comercialización (Garzón, 2016). Una vez reconocida la variedad o variedades más aptas, el paso final sería el de su implantación (mediante injertos) en las explotaciones de la Sierra de Aracena, para lo que se pondrían plantas madre a disposición de los titulares de las explotaciones.

Se trata a nuestro juicio de un proyecto muy interesante el impulsado desde este parque natural para la renovación y mejora del arbolado de castaño, en la línea, defendida en este trabajo, de fomentar intervenciones proactivas que respondan a los desafíos específicos de los usos agrarios y agrosistemas en el interior de las áreas protegidas.

\section{Discusión de resultados}

El análisis desarrollado y los resultados obtenidos cabe situarlos en el marco de una escasez general de trabajos en el contexto español acerca de la cuestión de la incidencia de las áreas protegidas en la ordenación y evolución de los usos agrarios.

En efecto, son pocas las aportaciones que se han podido rastrear desde dicha perspectiva básica. Entre esas aportaciones cabe destacar la de Fernández (2010) respecto del Parque Natural Regional del Vexin (Francia), que incorpora una visión integral muy interesante, analizando la evolución de los usos del suelo, en particular el espacio agrícola, y la incidencia en ello de los instrumentos de planificación, principalmente la Carta del Parque Natural Regional. También hay que reseñar algunos de los trabajos y proyectos desarrollados por EUROPARC-España, principalmente mediante casos de estudio en áreas protegidas determinadas (http://www.redeuroparc.org). En un sentido similar, aunque diferenciado, se hallan otras investigaciones que abordan en un sentido más general los cambios de uso del suelo en áreas protegidas, como por ejemplo los parques nacionales españoles (Hewitt, Pera y Escobar, 2016). E igualmente puede afirmarse de la cuestión de los usos agrarios en zonas periurbanas y metropolitanas, incluyendo medidas de protección para asegurar la preservación de tales usos como el Parque Agrario (con aportaciones recientes muy interesantes, como las de Zazo, Yacamán, entre otros).

Así pues, a tenor del panorama someramente descrito, no cabe sino remarcar la importante novedad que supone el análisis de la dinámica de los usos y paisajes agrarios como objetos de ordenación y gestión desde las áreas protegidas convencionales. Con todo, ello no significa que no se hayan analizado los usos y espacios agrarios sujetos a protección, ya que son numerosas las aportaciones que así lo han hecho, pero no desde la vinculación específica con la protección legal, sino más bien desde el enfoque más básico y 
general centrado en la descripción, valoración y diagnóstico de los agrosistemas, muchos de los cuales se localizan en el interior de grandes áreas protegidas diseñadas con criterios de multifuncionalidad (parques). Precisamente, algunas de las más destacadas aportaciones en esta línea se han centrado en la media montaña mediterránea, y más en particular en la Sierra Morena andaluza (Valle, 2001; Ojeda y Silva, 2002; Schröder, 2005; Lázaro y Vera, 2009; Mulero, 2013; Mulero y Silva, 2013; Zoido, Dir., 2012), sirviendo como soporte bibliográfico básico a este estudio, así como a posibles líneas de trabajo que profundicen en el mismo, como se apuntará en el apartado de Conclusiones.

\section{Conclusiones}

Después del estudio realizado, necesariamente sintético a tenor del espacio disponible, la constatación más evidente remite a la complejidad de la cuestión analizada. La propia diversidad agrosistémica y paisajística de una montaña media mediterránea humanizada y multifuncional como Sierra Morena, la disparidad de criterios entre parques naturales en la consideración y valoración de las distintas formaciones vegetales y agrosistemas, la incidencia de la normativa sectorial y los instrumentos de planificación ambiental de los parques, y la dinámica particularizada de los diferentes usos agrarios contribuyen a explicar la referida complejidad. Con todo, se pueden extraer una serie de conclusiones y enseñanzas básicas y de carácter general, que se sintetizan a continuación:

1) Los usos agrarios no han experimentado una merma desde la declaración de los parques naturales, sino antes bien una consolidación e incluso un reforzamiento, particularmente aquellos usos (forestales, cinegéticos y ganaderos) más favorecidos por la planificación ambiental, que ha resultado flexible y poco restrictiva en términos generales.

2) En el caso de la ordenación contenida en la planificación ambiental, y a propósito de lo apuntado en el punto anterior, resulta muy interesante la regulación básica de usos de los parques naturales de la Sierra Morena andaluza, impidiendo el retroceso desde formaciones forestales autóctonas a espacios de repoblación o agrícolas.

3) A pesar lo anterior, el trabajo desarrollado permite constatar la necesidad de una mejora de la planificación ambiental en favor de una ordenación más territorializada y adaptada a la especificidad de los usos agrarios y agrosistemas sustentadores de las áreas protegidas. A este respecto, se han detectado varios retos principales, como son:

- Una zonificación que, partiendo de los niveles básicos ya definidos (zonas A, B, y C), pudiese concretar más la delimitación de los agroecosistemas y formaciones existentes. La zonificación, una vez definida desde dicha perspectiva territorial y adaptativa, ha de llenarse de contenido a través de la regulación normativa y la dimensión proactiva.

- En cuanto a la normativa, esta debería resultar más concreta y actualizada en aspectos clave para la adecuada conservación de los recursos naturales y agrosistemas sustentadores de los usos agrarios. Así podrían abordarse impactos ambientales graves aún hoy día patentes en el interior de los parques naturales, como las cargas ganaderas excesivas en pastizales y dehesas, o los procesos erosivos severos en determinados cultivos en pendiente. La necesidad de un nuevo enfoque —-más decididamente territorial — para dicha ordenación podría concretarse en una regulación de los usos agrarios pero vinculados a los principales agroecosistemas presentes en cada parque natural, a modo de marco espacial bien reconocible. La regulación lo sería para la ganadería, la caza o las actividades agrícolas, pero en el marco de las dehesas ganaderas (o, en su caso, ganadero-cinegéticas), los espacios forestal-cinegéticos o las zonas de olivar. El marco territorial aportado por los agroecosistemas permitiría definir una regulación normativa más particularizada y efectiva de cada uno de los usos agrarios que los explican y dan forma.

- En consonancia con lo anterior, un impulso de la dimensión proactiva, incluyendo líneas de acción específicas y acompañadas de una programación bien definida, a corto-medio plazo, que permitiesen igualmente ofrecer una respuesta efectiva ante situaciones problemáticas, en la línea de lo que se viene planteando en años recientes para el castañar en el Parque Natural Sierra de Aracena y Picos de Aroche.

4) La incorporación de referencias territoriales a la ordenación de los usos y sistemas agrarios ha de acompañarse de mecanismos para su efectividad, lo que habría de articularse mediante una coordinación y colaboración entre todos los agentes (públicos y privados) encargados de la regulación y desarrollo de las actividades agrarias. Ello solo sería posible de una manera efectiva sobre la base 
de la implicación total de tales agentes en la definición de los criterios para la ordenación de los usos y sistemas agrarios, a través de un verdadero proceso participativo en la elaboración de los planes ambientales.

Tras estas conclusiones generales, finaliza esta aportación remarcando su carácter de trabajo panorámico y de base, que sin duda puede y debe ser objeto de una profundización ulterior. El trabajo abre la puerta a análisis más detallados, que, en función del enfoque, pueden asumir una doble orientación: territorial, a escala de cada parque natural (estudio pormenorizado de sus usos y paisajes agrarios), o temático (estudio de cada uno de los grandes usos agrarios considerados para los parques naturales de Sierra Morena). En todo caso, tales análisis habrían de abordar con mayor detalle aspectos que solo han podido apuntarse en este trabajo, como la incidencia más particular de la protección sobre los usos agrarios, su reflejo sobre los agrosistemas y su evolución, los impactos ambientales y su cuantificación dentro de las áreas protegidas, además de la proyección económica de la actividad agraria (papel de los agentes locales, entramados empresariales asociados a los usos agrarios, posibles marcas de calidad vinculadas a la protección,...).

\section{Anexos}

Anexo 1. Evolución superficial de los grandes agrosistemas (ha) en la Sierra Morena

\begin{tabular}{|c|c|c|c|r|}
\hline \multirow{2}{*}{ Agrosistemas } & $\begin{array}{c}1990 \\
\text { (Corine Land Cover) }\end{array}$ & $\begin{array}{c}2000 \\
\text { (Corine Land Cover) }\end{array}$ & $\begin{array}{c}2005 \\
\text { (SIOSE) }\end{array}$ & $\begin{array}{c}2018 \\
\text { (Corine Land Cover) }\end{array}$ \\
\hline $\mathrm{a}$ & 692.675 .340 & 711.490 .523 & 790.479 .348 & 877.645 .683 \\
\hline $\mathrm{b}$ & 1.276 .138 .774 & 1.051 .607 .593 & 1.333 .325 .914 & 1.394 .307 .208 \\
\hline $\mathrm{c}$ & 624.988 .215 & 563.860 .105 & 544.957 .236 & 529.897 .783 \\
\hline $\mathrm{d}$ & 1.412 .405 .855 & 1.448 .487 .763 & 1.453 .370 .498 & 1.491 .388 .639 \\
\hline $\mathrm{e}$ & 232.517 .772 & 231.583 .546 & 231.763 .435 & 17.534 .783 \\
\hline $\mathrm{f}$ & 11.384 .390 & 15.895 .410 & 16.437 .871 & 5.917 \\
\hline $\mathrm{g}$ & 6.668 & 8.608 & 7.485 & 66.300 .573 \\
\hline $\mathrm{h}$ & 69.291 .835 & 64.346 .348 & 65.478 .878 & 174.459 .749 \\
\hline $\mathrm{i}$ & 142.191 .626 & 141.725 .593 & 143.412 .460 & 377.973 .592 \\
\hline $\mathrm{j}$ & 208.818 .286 & 381.769 .365 & 378.805 .350 & \\
\hline
\end{tabular}

a. Formaciones arboladas densas de quercíneas

b. Formaciones arboladas de quercíneas con matorral

c. Formaciones de matorral

d. Formaciones arboladas de quercíneas con herbáceos (dehesas)

e. Olivares

f. Otros cultivos leñosos

g. Castañares

h. Eucaliptales

i. Pastizales

j. Repoblaciones forestales de Pinus spp

Fuente: Bases cartográficas referidas en la tabla. Elaboración propia

Anexo 2. Evolución superficial de los grandes agrosistemas (ha) en los parques naturales de la Sierra Morena andaluza

\begin{tabular}{|c|c|c|c|c|}
\hline Agrosistemas & $\begin{array}{c}1990 \\
\text { (Corine Land Cover) }\end{array}$ & $\begin{array}{c}2000 \\
\text { (Corine Land Cover) }\end{array}$ & $\begin{array}{c}2005 \\
\text { (SIOSE) }\end{array}$ & $\begin{array}{c}2018 \\
\text { (Corine Land Cover) }\end{array}$ \\
\hline $\mathrm{a}$ & 69.268 & 71.149 & 79.048 & 87.765 \\
\hline $\mathrm{b}$ & 127.634 & 132.161 & 133.333 & 139.431 \\
\hline $\mathrm{c}$ & 62.499 & 56.386 & 54.496 & 52.990 \\
\hline $\mathrm{d}$ & 141.241 & 144.849 & 145.337 & 149.139 \\
\hline $\mathrm{e}$ & 23.252 & 23.178 & 23.176 & 23.172 \\
\hline $\mathrm{f}$ & 1.858 & 1.690 & 1.664 & 1.653 \\
\hline $\mathrm{g}$ & 8.668 & 8.708 & 7.485 & 5.917 \\
\hline $\mathrm{h}$ & 6.929 & 6.435 & 6.548 & 6.630 \\
\hline i & 14.219 & 14.173 & 14.341 & 17.446 \\
\hline $\mathrm{j}$ & 41.882 & 38.177 & 37.881 & 37.797 \\
\hline
\end{tabular}

Fuente: Bases cartográficas referidas en la tabla. Elaboración propia 


\section{Referencias}

Chape, S., Spalding, M. y Jenkins, M. (Eds.) (2008). The World's Protected Areas: Status, Values and Prospects in the $21^{\text {st }}$ Century. Berkeley: University of California Press.

Consejería de Medio Ambiente (2003/2004). Planes de Ordenación de los Recursos Naturales y Planes Rectores de Uso y Gestión (Parques Naturales). Sevilla: Junta de Andalucía. Recuperado de http://www. juntadeandalucia.es/medioambiente

Coronado, A. (2020). Umbrales. Paisajes de transición entre conjuntos urbanos y ruedos agrícolas de la Sierra Morena de Huelva (Tesis doctoral). Universidad de Sevilla. https://idus.us.es/handle/11441/100103

Corraliza, J. A., Valero, E. y García, J. (2002). Los Parques Naturales en España: conservación y disfrute. Madrid: Fundación Alfonso Martín Escudero.

Dudley, N. (Ed.) (2008). Guidelines for Applying Protected Areas Management Categories. Gland: IUCN. https://doi.org/10.2305/IUCN.CH.2008.PAPS.2.en

Fernández, C. (2010). Los usos agrícolas en el Parque Natural Regional del Vexin francés. Un área rural a las puertas del gran París en riesgo de gentrificación. En M. Vázquez y C. Verdaguer (Dirs.), El espacio agrícola entre el campo y la ciudad. Recuperado de http://habitat.aq.upm.es/eacc/

Garzón, R. (2016). Las consecuencias territoriales de la expansión reciente de los espacios naturales protegidos: Análisis de la Sierra Morena andaluza (Tesis Doctoral). Universidad de Córdoba. https://helvia.uco.es/ xmlui/handle/10396/13259

Garzón, R. y Ramírez, L. (2016). Una reflexión actual sobre la vinculación desarrollo rural-áreas protegidas a partir de la experiencia de la Sierra Morena andaluza. En A. Ruiz, M.A. Serrano y J. Plaza, (Eds.), Treinta Años de Política Agraria Común en España. Agricultura y multifuncionalidad en el contexto de la nueva ruralidad (pp. 366-383). Recuperado de https://www.age-geografia.es/site/wpcontent/uploads/2020/01/Dialnet-TreintaAnosDePoliticaAgrariaComunEnEspana-660685.pdf

Gómez, A. (2007). Componentes del valor del paisaje mediterráneo y el flujo de servicios de los ecosistemas. Ecosistemas, 16(3), 97-108. Recuperado de https://www.revistaecosistemas.net/index. php/ecosistemas/article/view/117

González, F. (1992). La frutalización del paisaje mediterráneo. En Y. Luginbühl (Coord.), Paisaje mediterráneo (pp. 136-141). Milán: Electa.

Hewitt, R., Pera, F. y Escobar, F. (2016). Cambios recientes en la ocupación del suelo en los parques nacionales españoles y su entorno. Cuadernos Geográficos, 55, 46-84. Recuperado de https:// revistaseug.ugr.es/index.php/cuadgeo/article/view/3130

Lasanta, T., Álvarez, J. y Gómez-Villar, A. (2014). La ganadería extensiva frente a la matorralización: actuaciones recientes en las montañas españolas. En J. Cortizo (Coord.), De la geografía rural al desarrollo local (pp. 491-503). León: Universidad de León.

Lázaro, M. y Vera, A. (2009). La gestión sostenible del paisaje de dehesa en la Sierra Morena andaluza. En VV.AA., Geografía, Territorio y Paisaje: el estado de la cuestión. Actas del XXI Congreso de Geógrafos Españoles (pp. 1147-1160). Ciudad Real: Universidad de Castilla-La Mancha-AGE.

Ley 42/2007, de 13 de diciembre, del Patrimonio Natural y la Biodiversidad (BOE núm. 299, de 14 de diciembre de 2007).

López, E. (2002). Posibilidades de desarrollo en los parques naturales de Sierra Morena a la luz de los condicionamientos de los PORN y los PRUG. En P. Pumares, M. A. Asensio y F. Fernández (Coord.), Turismo y transformaciones urbanas en el siglo XXI (pp. 251-262). Almería: Universidad de Almería.

Martínez, J. y Martín, M. A. (2003). Métodos para la planificación de espacios naturales protegidos. Madrid: CSIC.

Mata, R. (2012). Retorno al paisaje mediterráneo. Cultura territorial, conflictos y políticas. En V. Gozálvez, V. y J. A. Marco (Eds.), Geografía: retos ambientales y territoriales. XXII Congreso de Geógrafos Españoles (pp. 17-65). Alicante: AGE-Colegio de Geógrafos de España-Universidad de Alicante.

Mazurek, H. y Blanchemanche, P. (1992). La organización del paisaje rural mediterráneo de los pueblos a las fincas de pastoreo. En Y. Luginbühl (Coord.), Paisaje mediterráneo (pp. 142-153). Milán: Electa. 
McDonald, R. y Boucher, T. (2011). Global development and the future of the protected area strategy. Biological Conservation, 144(1), 383-392. https://doi.org/10.1016/j.biocon.2010.09.016

Mulero, A. (2001). Sierra Morena como espacio protegido. Del olvido tradicional al interés reciente. Investigaciones Geográficas, 25, 51-66. Recuperado de http://dx.doi.org/10.14198/INGEO2001.25.06

Mulero, A. (2013). El paisaje forestal-cinegético en Sierra Morena: una lectura geográfica. Cuadernos Geográficos, 52, 108-128. Recuperado de https://revistaseug.ugr.es/index.php/cuadgeo/article/ view/928

Mulero, A. y Garzón, R. (2005). Desarrollo rural y espacios protegidos: confusión e ineficacia en torno a los Planes de Desarrollo Sostenible. Ería, 68, 315-330. Recuperado de https://www.unioviedo.es/ reunido/index.php/RCG/article/view/1523

Mulero, A. y Silva, R. (2013). Paisajes de Sierra Morena: una cuestión de miradas y escalas. Revista de Estudios Regionales, 96, 35-64. Recuperado de http://www.revistaestudiosregionales.com/documentos/ articulos/pdf1204.pdf

Naughton-Treves, L., Holland, M. y Brandon, K. (2005). The role of Protected Areas in Conserving Biodiversity and Sustaining Local Livelihoods. Annual Review of Enviromental Resources, 30, 219-250. https://doi.org/10.1146/annurev.energy.30.050504.164507

Ojeda, J. F. (2006). Paisaje y orden territorial en la montaña media mediterránea. En R. Mata y A. Tarroja (Coord.), El paisaje y la gestión del territorio (pp. 181-186). Barcelona: Diputació de Barcelona.

Ojeda, J. F. y Silva, R. (2002). Aproximación a los paisajes de la Sierra Morena andaluza. En F. Zoido y C. Venegas (Coords.), Paisajes y Ordenación del Territorio (pp. 71-91). Sevilla: Fundación Duques de Soria - Consejería de Obras Públicas y Transportes.

Phillips, A. (2003). Un paradigma moderno. Conservación Mundial, 2, 6-7.

Rivera, R. (1992). Explotación agraria y ocupación del espacio productivo en Sierra Morena. Córdoba: Universidad de Córdoba.

Roux, B. (1975). Crisis agraria en la sierra andaluza: un estudio económico de las empresas ganaderas de la provincia de Huelva. Sevilla: Universidad de Sevilla.

Rubio, M. (2011). El castañar de la Sierra de Aracena (Huelva): el abandono de un territorio simbólico. En F. Molinero, J. F. Ojeda y J. Tort (Coords.), Los paisajes agrarios de España. Caracterización, evolución y tipificación (pp. 482-490). Madrid: Ministerio de Medio Ambiente, Medio Rural y Marino.

Sánchez, J. D. (2009). La repoblación forestal en Andalucía (1940-2006): una aproximación inicial. En E. Araque y J. D. Sánchez (Coord.), Repoblación forestal en Andalucía (pp. 71-122). Jaén, Universidad de Jaén.

Schröder, C. (2005). Dinámica de las dehesas de Sierra Morena. Sevilla: Junta de Andalucía, Consejería de Medio Ambiente.

Silva, R. y Ojeda, J. F. (1997). Dehesas de Sierra Morena y Políticas Agroambientales Comunitarias. Estudios Geográficos, 227, 203-226. https://doi.org/10.3989/egeogr.1997.i227.626

Silva, R. (2010). La dehesa: de la pauperización desarrollista a la revalorización postmoderna. En F. Molinero, J. F. Ojeda y J. Tort (Coords.), Los Paisajes Agrarios de España (pp. 479-497). Madrid: Ministerio de Medio Ambiente, Medio Rural y Marino.

Spellerberg, I. (1994). Evaluation and Assessment for Conservation. Londres: Chapman \& Hall.

Valle, B. (1981). Los paisajes agrarios de Sierra Morena. Su relación con la estructura de la propiedad y de las explotaciones. En La propiedad de la tierra en España (pp. 449-465). Alicante: Universidad de Alicante, Departamento de Geografía.

Valle, B. (2001). Sierra Morena: de espacio agrario a espacio protegido. En F. Manero (Coord.), Espacio natural y dinámicas territoriales (pp. 383-396). Valladolid: Universidad de Valladolid.

Zoido, F. (2007). Paisaje y ordenación territorial en ámbitos mediterráneos. En El paisaje mediterráneo. Opciones de multifuncionalidad (pp. 92-100). Valencia: Fundación Santander Central Hispano.

Zoido, F. (Dir.) (2012). Inventario de recursos paisajísticos de la Sierra Morena andaluza. Sevilla: Junta de Andalucía (REDIAM) - Centro de Estudios Paisaje y Territorio. Recuperado de https://www. juntadeandalucia.es/medioambiente 